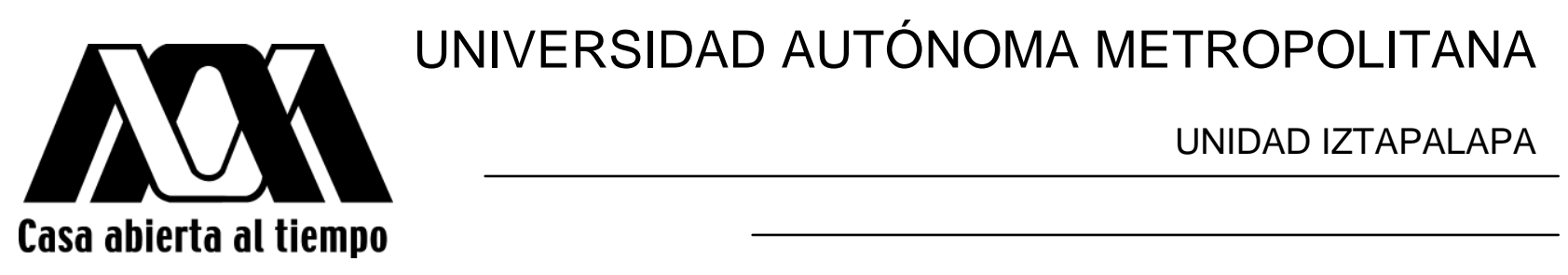

DIVISIÓN DE CIENCIAS BIOLÓGICAS Y DE LA SALUD

POSGRADO EN BIOLOGÍA EXPERIMENTAL

\title{
EFECTO DE LA PRIVACIÓN DE SUEÑO MOR SOBRE MARCADORES METABÓLICOS E INFLAMATORIOS EN RATAS
}

TESIS

QUE PARA OBTENER EL GRADO DE MAESTRA EN BIOLOGÍA EXPERIMENTAL

P R E S E N T A :

Bióloga Experimental Malinalli Brianza Padilla

Directores:

Dr. Gonzalo Vázquez Palacios

Dra. Herlinda Bonilla Jaime

Asesor:

Dr. Julio César Almanza Pérez

México D.F. 26 de Julio de 2012 


\title{
Comité Tutoral
}

\author{
Co-directora \\ Dra. Herlinda Bonilla Jaime \\ Profesor - Investigador Titular C \\ Departamento de Biología de la Reproducción \\ Universidad Autónoma Metropolitana - Iztapalapa
}

\author{
Co-director \\ Dr. Gonzalo Vázquez Palacios \\ Profesor - Investigador \\ Colegio de Ciencia y Tecnología \\ Universidad Autónoma de la Ciudad de México \\ San Lorenzo Tezonco \\ Asesor \\ Dr. Julio César Almanza Pérez \\ Profesor Investigador - Titular C \\ Departamento de Ciencias de la Salud \\ Universidad Autónoma Metropolitana - Iztapalapa
}


El presente trabajo fue realizado en la Universidad Autónoma Metropolitana Unidad Iztapalapa, en el laboratorio de biología conductual y reproductiva, bajo la Codirección de la Dra. Herlinda Bonilla Jaime y el Dr. Gonzalo Vázquez Palacios, y en el laboratorio de Farmacología bajo la asesoría del Dr. Julio César Almanza Pérez. La alumna Malinalli Brianza Padilla recibió una beca CONACyT, con el número de registro (CVU/Becario) 372651/248825. 


\section{Miembros de Jurado}

Los miembros del jurado fueron designados por la comisión académica del posgrado en Biología Experimental de la División de Ciencias Biológicas y de la Salud de la Universidad Autónoma Metropolitana, unidad Iztapalapa, los abajo firmantes aprobaron la tesis titulada "Efecto de la privación de sueño MOR sobre marcadores metabólicos e inflamatorios en ratas", con fecha de presentación para obtener el grado de Maestría, el día 26 de Julio de 2012.

\section{Dr. Julio César Almanza Pérez}

Laboratorio de Farmacología

Departamento de Ciencias de la Salud

Universidad Autónoma Metropolitana- Iztapalapa

(Presidente)

\section{Dr. Fausto Sánchez Muñoz}

Departamento de Inmunología

Instituto Nacional de Cardiología (Ignacio Chávez)

(Secretario)

\section{Dra. Renata Saucedo García}

Unidad de Investigación Médica de Enfermedades Endócrinas

Hospital de Especialidades

Centro Médico Nacional Siglo XXI

(Vocal)

\section{Dr. José Alberto Barradas Bribiesca}

Departamento de Psicología

División de Ciencias de la Salud

Universidad de Guanajuato, campus León

(Vocal) 


\section{Dedicatoria}

\section{A Hasen}

Mi fuente de vida, mi motor, mi motivo de lucha, mi más grande impulso para mantenerme con fortaleza y perseverancia, a mi compañero de sueños, de sonrisas ... el mas grande de los regalos que me ha otorgado la vida.

Gracias hijo hermoso por estar aquí.

Te amo inmensamente

"La vida es hermosa, vivirla no es una casualidad" *Albert Einstein 


\section{Agradecimientos}

\section{A mis directores y asesor}

Por su apoyo incondicional, por su paciencia, por siempre creer en mí y por tantas enseñanzas tanto académicas como de vida.

\section{Al jurado evaluador}

Por su objetividad y apoyo, sus comentarios siempre puntuales le otorgaron mayor calidad a este trabajo

\section{A mis compañeros de laboratorio}

Por los momentos compartidos y los momentos de alegría.

\section{A mis amigos}

Complemento de mi vida y el soporte de mis ideales, por las manos honestas que no permiten derrotas ni declives.

\section{A mi familia}

Por el apoyo y el amor

\section{A Daniel}

Por educarme emocionalmente y guiarme para encontrar una forma diferente de vivir.

"Hay dos formas de educación: la que te enseña a ganarte la vida y la que te enseña a vivir" *Anthony De Mello 


\section{ÍNDICE}

\section{Página}

1. Abreviaturas $\quad 7$

2. Resumen 8

3. Abstract 10

4. Introducción 11

5. Antecedentes 14

5.1 Generalidades del sueño 14

5.1.1 Funciones generales del sueño 17

5.1.2 Funciones del sueño MOR 19

5.2 Privación de sueño 20

5.2.1 Métodos de Privación de sueño MOR 21

5.2.2 Privación de sueño e impacto en la calidad de vida 23

5.3 Generalidades del metabolismo $\quad 25$

5.3.1 Regulación hormonal de metabolismo 26

5.3.2 Trastornos del metabolismo $\quad 29$

5.3.3 Regulación sueño - metabolismo 31

5.3.4 Privación de sueño MOR y metabolismo 33

6. Justificación 34

7. Pregunta de Investigación 35

8. Hipótesis 35

9. Objetivos 36

9.1 Objetivos particulares 36

10. Diseño experimental 37

10.1 Modelo experimental $\quad 37$

10.2 Método de plataformas múltiples para privación de sueño MOR 38

10.3 Evaluación de parámetros bioquímicos 39

10.4 Prueba de tolerancia a la glucosa oral 40

10.5 Ensayo por inmuno-absorción ligado a enzimas (ELISA) 41

10.6 Análisis estadístico 41

11. Resultados 42

11.1 Efecto de la PSMOR sobre el peso corporal 42

11.2 Efecto de la PSMOR sobre la PTGO 43

11.3 Efecto de la PSMOR sobre los niveles de insulina 45

11.4 Efecto de la PSMOR sobre el panel de lípidos 46

11.5 Efecto de la PSMOR sobre los niveles de corticosterona 48

11.6 Efecto de la PSMOR sobre los niveles de grelina y leptina 49

11.7 Efecto de la PSMOR sobre los niveles de IL-6 51

11.8 Integración de resultados $\quad 52$

12. Discusión $\quad 54$

13. Conclusión $\quad 71$

14. Referencias 


\section{ABREVIATURAS}

\begin{tabular}{|c|c|}
\hline $\begin{array}{l}\text { CRF } \\
\text { DT2 }\end{array}$ & $\begin{array}{l}\text { Factor liberador de corticotropina } \\
\text { Diabetes mellitus tipo } 2\end{array}$ \\
\hline EEG & Electroencefalograma \\
\hline EMG & Electromiograma \\
\hline EOG & Electroculograma \\
\hline FRP & Formación reticular pontina \\
\hline GH & Hormona de crecimiento \\
\hline HA & Hipertensión arterial \\
\hline HHA & Eje hipotálamo-hipófisis-adrenal \\
\hline HDL & Lipoproteína de alta densidad \\
\hline IG & Intolerancia a la glucosa \\
\hline IL-1 $\beta$ & Interleucina tipo $1 \beta$ \\
\hline IL-6 & Interleucina tipo 6 \\
\hline IMC & Índice de masa corporal \\
\hline LDL & Lipoproteína de baja densidad \\
\hline MOR & Movimientos oculares rápidos \\
\hline MPM & Método de plataformas múltiples \\
\hline NMOR & No movimientos oculares rápidos \\
\hline P-CR & Proteína C reactiva \\
\hline PTAS & Privación total aguda de sueño \\
\hline PPARs & Receptores activados de proliferación de peroxisomas \\
\hline PPCS & Privación parcial crónica de sueño \\
\hline PPS & Privación parcial de sueño \\
\hline PS & Privación de sueño \\
\hline PSA & Privación de sueño aguda \\
\hline PSMOR & Privación de sueño de movimientos oculares rápidos \\
\hline PSOL & Privación de sueño de ondas lentas \\
\hline PSS & Privación de selectiva de sueño \\
\hline PTGO & Prueba de tolerancia a la glucosa oral \\
\hline PTS & Privación total de sueño \\
\hline $\mathbf{R} \mathbf{I}$ & Resistencia a la insulina \\
\hline SNC & Sistema nervioso central \\
\hline SM & Síndrome metabólico \\
\hline SMOR & Sueno de movimientos oculares rápidos \\
\hline SOL & Sueño de ondas lentas \\
\hline TG & Tolerancia a la glucosa \\
\hline $\begin{array}{l}\text { TNFa } \\
\text { VLDL }\end{array}$ & $\begin{array}{l}\text { Factor de necrosis tumoral tipo } \alpha \\
\text { Lipoproteína de muy baja densidad }\end{array}$ \\
\hline
\end{tabular}




\section{RESUMEN.}

El sueño es una condición biológica imprescindible, se caracteriza por una conducta de pasividad y disminución de la respuesta a estímulos externos. El sueño se ha dividido en dos fases: la fase de sueño de ondas lentas (SOL) y la fase de sueño de movimientos oculares rápidos (SMOR), la que se presenta una pérdida del tono muscular, acompañada de la mayoría de las ensoñaciones que se presentan a lo largo del sueño. La privación de esta fase de sueño es el objeto de estudio del presente trabajo.

La modernidad de los medios de comunicación, las jornadas laborales excesivas, la rotación de turnos laborales, etc. han favorecido a la disminución en las horas de sueño, esto tiene efecto no solo en el desempeño laboral y social, sino también en la salud de la personas, pues cada vez existen más evidencias de que la privación de sueño (PS) contribuye al incremento en la incidencia de enfermedades metabólicas.

El objetivo de este trabajo fue determinar las alteraciones que pueden provocar diferentes periodos de privación de sueño de movimientos oculares rápidos (PSMOR), así como un periodo de recuperación de 20 días posterior a 8 días de PSMOR sobre los niveles de glucosa y su comportamiento en la prueba de tolerancia a la glucosa oral (PTGO), niveles de insulina, IL-6 y hormonas relacionadas con la ingesta de alimento (grelina y leptina), así como las concentraciones de corticosterona como marcador general de inducción a estrés fisiológico. Para el desarrollo del proyecto se utilizó como modelo rata macho Wistar de 3 meses de edad, en 4 grupos experimentales con $n=5$ por experimento independiente: 1 día de PSMOR, 4 días de PSMOR, 8 días de PSMOR y 8 días de PSMOR con 20 días de recuperación, para cada experimento de realizó la PTGO en 5 tiempos de observación, posteriores a la administración de dextrosa anhidra y el perfil de lípidos en sangre total. Las citocinas y hormonas se analizaron por la técnica de ELISA, también se evaluó el peso corporal durante y después de la PSMOR. Los animales 
del grupo control fueron mantenidos durante los mismos periodos en la caja de privación de sueño pero solo con aserrín. Para el análisis estadístico, los resultados se presentan como $\mathrm{M} \pm \mathrm{EEM}$. En todos los casos se utilizó un análisis de varianza, y para encontrar diferencias entre grupos se utilizaron pruebas de comparaciones múltiples (Tukey y Newman-Keuls), la totalidad de las pruebas estadísticas se efectuaron en el programa GB-STAT.

Los resultados reflejan una disminución progresiva del peso corporal dependiente del tiempo de PSMOR, dicho efecto no puede ser reversible a pesar de transcurrir 20 días de recuperación. La PSMOR induce hipoglucemia en todos los tiempos, sin embargo la recuperación provoca un incremento en las concentraciones de glucosa. En cuanto a la insulina se observa una disminución en la concentración desde el día 1 de PSMOR, misma que se restablece posterior al periodo de recuperación. La PSMOR causa disminución en los niveles de triglicéridos, lipoproteínas de alta densidad (HDL), lipoproteínas de muy baja densidad (VLDL) e incrementos en la concentración de lipoproteínas de baja densidad (LDL). La PSMOR induce un incremento en los niveles de corticosterona a los 8 días de PSMOR, condición que se mantiene luego de 20 días de recuperación. La PSMOR por 8 días también induce un incremento en los niveles de grelina y una disminución progresiva en los niveles de leptina. Las concentraciones de IL-6 se incrementan por efecto de la PSMOR, sin embargo, después de 20 días de recuperación estos niveles no se restablecen.

Concluimos que los efectos metabólicos inducidos por la PSMOR son dependientes de su duración, algunas alteraciones fisiológicas inducidas por la PSMOR como el peso corporal, IL-6, corticosterona y glucosa, no se restablecen después de un periodo de recuperación de 20 días. 


\section{ABSTRACT}

Sleep is a biological imperative condition is characterized by a pattern of passivity and decreased response to external stimuli. Sleep is divided into two phases: the phase of slow wave sleep (SWS) and the phase of rapid eye movement sleep (SMOR), which shows a loss of muscle tone, accompanied by most of the dreams that occur during sleep. The deprivation of this phase of sleep is the object of study of this work. The modernity of the media, excessive working hours, rotating shift work, etc. have contributed to the decline in sleep, this has an effect not only on labor and social performance, but also the health of the people because there is increasing evidence that sleep deprivation (PS) contributes to increased incidence of metabolic diseases. The aim of this study was to determine the alterations that can cause various periods of deprivation of rapid eye movement sleep (PSMOR) and a recovery period of 20 days after 8 days of PSMOR on glucose levels and performance in oral glucose tolerance test (OGTT), insulin, IL-6 and hormones involved in food intake (ghrelin and leptin) and corticosterone concentrations as a general marker of physiological stress induction. To do this, We used male Wistar rats 3 months old in 4 independent experimental groups with an $n=5$ : 1 day PSMOR, PSMOR 4 days, 8 days and 8 days PSMOR with 20 days of recovery for each experiment performed OGTT in 5 days of observation after administration of anhydrous dextrose and lipid profile in whole blood. Cytokines and hormones were analyzed by ELISA, was also assessed body weight during and after the PSMOR. Control animals were kept in the same periods in the box of sleep deprivation but only with sawdust. For statistical analysis, the results are presented as Media \pm SEM. In all cases we used analysis of variance, and to find differences between groups were used multiple comparison tests (Tukey and Newman-Keuls). All statistical tests were performed in the GB-STAT program. The results show a progressive decrease in body weight PSMOR timedependent, this effect cannot be reversible although recovery after 20 days. The PSMOR induced hypoglycemia in all times, however the recovery causes an increase in glucose concentrations. As to insulin is a decrease in concentration from day 1 of 
PSMOR; it was restored after recovery period. The PSMOR cause decreased levels of triglycerides, high density lipoprotein (HDL), low density lipoprotein (VLDL) and increases in the concentration of low density lipoprotein (LDL). The PSMOR induces an increase in corticosterone levels after 8 days of PSMOR, a condition that remains after 20 days of recovery. The PSMOR for 8 days also induces an increase in ghrelin levels and a progressive decrease in leptin levels. Concentrations of IL-6 increased the effect of PSMOR, however after 20 days of recovery these levels are not restored. We conclude that the metabolic effects induced PSMOR are dependent on its duration, some physiological alterations induced by PSMOR such as loss body weight, increases in IL-6, corticosterone and glucose, are not restored after a recovery period of 20 days.

\section{INTRODUCCIÓN}

El dormir es una actividad fisiológica de indudable relevancia, caracterizada por una conducta de pasividad y una disminución en la capacidad de respuesta a estímulos externos (Jones, 1998). Una de las características neurobiológicas del sueño es su división en dos fases: fase de movimientos oculares rápidos (MOR) y fase no MOR o también conocido como sueño de ondas lentas (SOL), como su nombre lo indica el movimiento ocular marca una diferencia entre una fase y otra, es en el sueño MOR (SMOR) donde existe atonía muscular acompañada con la mayor cantidad de ensoñaciones, además de la presencia de características polisomnográficas similares a las que presenta el estado de vigilia o el estar despierto (Nilsson, 2004).

Con el paso de los años y la modernización de los medios de comunicación, las horas de sueño de los seres humanos se han ido reduciendo de manera progresiva, afectando no solo el desempeño laboral y social, sino también la salud de la persona que está durmiendo menos tiempo. Una de las enfermedades multifactoriales que pueden asociarse con la carencia de sueño es la diabetes mellitus tipo 2 (DT2), la cual representa un grave problema de salud pública por su alta prevalencia e impacto 
económico y social, por lo que es necesario buscar formas de disminuir la incidencia y mortalidad. Hasta ahora los factores adquiridos más comunes y reconocidos que contribuyen al desarrollo de la DT2 tienen que ver con la falta de actividad física y la elevada ingesta de alimentos ricos en carbohidratos y lípidos. Sin embargo, cada vez hay más evidencia de que el estilo de vida moderna: la privación y el acortamiento del dormir, también están contribuyendo al aumento en la incidencia de esta enfermedad (Knutson, 2008; Barone, 2011). En la actualidad, hay un limitado reconocimiento público sobre la importancia del dormir en relación a la salud y en particular sobre la DT2 y el síndrome metabólico (SM). En la literatura existen pocos estudios que consideran a la privación de sueño (PS) como un factor de riesgo para la aparición, desarrollo o agravamiento de la DT2.

Sin embargo, estudios epidemiológicos, tanto transversales como prospectivos, han mostrado que la corta duración y la baja calidad de sueño predicen el desarrollo de DT2 y obesidad (Spiegel, 2009).

La mayoría de los trabajos sobre privación de sueño han sido aislados, puntualizando en algún parámetro en particular (si se elevan o disminuyen los niveles de algunas moléculas o el efecto de la administración exógena de alguna sustancia sobre la organización del sueño) y en la mayoría de los casos han mostrado una correlación estadística entre PS y DT2. En algunos estudios se sugieren relaciones y nuevas hipótesis de acuerdo a los resultados, pero por desgracia muy pocas de estas líneas sugeridas han sido corroboradas en subsecuentes trabajos o han generado líneas de investigación que abarquen más allá de la participación de alguna sustancia y/o molécula en la regulación del sueño a nivel cerebral, sin realizar un estudio de los efectos provocados a nivel sistémico. Solo en algunos casos se ha intentado integrar o correlacionar al sueño con la aparición y desarrollo de algún problema de salud o patología específica. Aunado a esto los métodos de PS aún no se tienen bien estandarizados y hasta tiempos recientes se han cuestionado los efectos de factores de estrés intrínsecos inducidos por los propios procedimientos de PS habituales como la manipulación, el aislamiento, la inmovilidad o la restricción del 
movimiento. De hecho, la naturaleza y la relación causa-efecto entre las consecuencias inducidas por la PS, en sus diferentes variantes, en particular la PSMOR sobre la aparición, el desarrollo o agravamiento de la DT2 es incierta y requiere ser explorada sistemáticamente y a mayor profundidad.

Ante todo lo anterior, la mayoría de las referencias del presente trabajo se refieren a estudios epidemiológicos en humanos y pocos estudios experimentales en ratas. Asimismo no existe una revisión sobre la integración de todas estas, acerca de los efectos de la PS experimental (en humanos o animales) y la salud.

Entre las particularidades que se conocen, el sueño podría tener un efecto importante sobre el peso corporal, debido a sus funciones reguladoras sobre el apetito y la función endocrina, esto aunado a que el tejido adiposo juega un papel endocrino importante para la regulación del apetito al secretar hormonas como la leptina, el mismo tejido adiposo tiene la capacidad de inducir procesos inflamatorios por la liberación de factores pro-inflamatorios como el factor de necrosis tumoral (TNF- $\alpha$ ) y la interleucina 6 (IL-6) por mencionar algunos. Es posible que la producción elevada de citocinas pro-inflamatorias sea un factor de riesgo importante para desencadenar resistencia a la insulina y DT2. Cuando existe obesidad y/o DT2 la patología normalmente se acompaña de hipertrigliceridemia e hipercolesterolemia, entre los tratamientos mas utilizados para la DT2 se encuentran algunos hipoglucemiantes como la tiazolidinediona que inducen la activación de los receptores de proliferación de peroxisomas (PPAR's), los cuales se expresan principalmente en el tejido adiposo y entre sus funciones está la de sensibilizar a la insulina, lo que significa que la presencia de estos receptores podría favorecer la homeostasis de la glucosa. (Hauner, 2005). Por todo lo anterior se considera que puede existir una relación importante entre la ausencia de sueño y la falta de regulación metabólica en lípidos y glucosa, así como una modificación en el comportamiento de hormonas reguladoras del apetito. 
El objetivo del presente proyecto fue determinar los cambios que pueden provocar diferentes periodos de PSMOR sobre los niveles de glucosa, insulina, IL-6, hormonas relacionadas con la ingesta de alimento y otros componentes metabólicos en la rata, con base en la hipótesis general que supone que la privación total (PT), parcial o selectiva de sueño (como la PSMOR), pueden inducir alteraciones en el metabolismo energético y/o en la respuesta inflamatoria.

\section{ANTECEDENTES}

\subsection{Generalidades del sueño}

El sueño se ha definido como un estado de quietud conductual, acompañado de una postura de inmovilidad característica en cada especie, con una disminuida capacidad de respuesta a estímulos. El sueño está constituido por diferentes fases y estados que se presentan de manera cíclica. Las fases del dormir se definen según los patrones característicos que se observan mediante el electroencefalograma (EEG), el electroculograma (EOG) y el electromiograma (EMG). Estos perfiles generan dos estados del sueño que se alternan a lo largo de la noche: el sueño MOR y el sueño no MOR o también conocido como sueño de ondas lentas (SOL). Con base en la actividad EEG el SOL se subdivide en 3 etapas (N1, N2 y N3) (Silber, 2007) que en orden creciente reflejan la integración del conjunto de encéfalo en frecuencias progresivamente mas lentas, la etapa mas profunda N3, se vincula con la restauración somática y la regulación de la liberación hipofisiaria de hormona de crecimiento. (Van Cauter, 1999).

En SMOR la actividad del EMG permanece ausente, reflejando la atonía muscular, característica importante de esta fase (Nilsson, 2004). La visión actual de la regulación fisiológica del sueño sostiene que hay dos componentes en la regulación: 1) la necesidad homeostática del sueño que se manifiesta por un aumento de la propensión a dormir después de la PS y la disminución de esta propensión al dormir, 
a este proceso se le denomina componente homeostático, y 2) un marcapasos circadiano ( $24 \mathrm{~h}$ ), que es básicamente independiente del sueño y la vigilia, pero que determina los tiempos de inicio y terminación del sueño mediante el cambio del umbral de la necesidad del dormir (Borbely, 1982). Tanto el marcapasos circadiano como el componente homeostático del dormir contribuyen a la consolidación del sueño. La interacción entre estos procesos son la base para consolidar el sueño por la noche y una presión para dar paso a la vigilia durante el día. Así, la propensión a dormir depende de la cantidad de PS y del ciclo circadiano.

Los niveles de excitación y el estrés también desempeñan un papel fundamental en el proceso de inducción del sueño, un elevado nivel de excitación está asociado con una disminución de la propensión al sueño y viceversa (Germain, 2003). Estos factores pueden ser fácilmente interrumpidos por influencias exógenas tales como la PS, alteraciones de los horarios laborales y el uso de medicamentos o la presencia de algunas enfermedades.

Cuando hablamos de roedores, en caso específico de la rata, el ciclo sueño-vigilia es polifásico, con mayor cantidad de sueño durante la fase luminosa o de reposo y una mayor actividad durante la fase oscura. Hablando puntualmente de SMOR, este se puede registrar polisomnográficamente tanto en la corteza como en la formación hipocámpica. La duración de cada episodio de SMOR en la rata es muy variable de 1-5 minutos o más, el inicio de un episodio de SMOR está marcado por la pérdida total de tono muscular principalmente en el cuello, además de la presencia de actividad rápida en EEG, el final de un episodio de SMOR está delimitado por la recuperación súbita del tono muscular, ya sea para pasar a la vigilia o regresar a SOL, la atonía muscular coexiste con activaciones fásicas del resto de la musculatura, que se manifiesta en forma de sacudidas repentinas y bruscas, movimientos de vibrisas, orejas y cola. (Borbély y Tobler, 1985).

El ciclo sueño-vigilia es una manifestación básica de la actividad del sistema nervioso central (SNC) a la vez que es regulado por diversas estructuras cerebrales. Siendo 
principalmente que la modulación de SOL depende preferentemente de estructuras rostrales: prosencefálicas, mientras que la modulación del SMOR depende de estructuras romboencefálicas y/o del tronco cerebral. (Próspero y Drucker, 1996). Así mismo se sabe que el hipotálamo posterior envía fibras histaminérgicas difusas a la corteza y al tálamo, conexiones consideradas como parte del sistema activador de la vigilia, pues su lesión produce somnolencia continua (Nauta, 1946).

El área preótica medial juega un papel importante en el control del sueño, así como en el control de otras funciones fisiológicas como la temperatura. Cuando es lesionada esta estructura causa alteraciones en el SOL y en el SMOR (Asala, 1990). Por otra parte el núcleo accumbens presenta células neuronales que se activan preferentemente durante la vigilia y el SMOR (Próspero y Druker, 1996). Y también se sabe que el tronco cerebral contiene una gran variedad de núcleos que modulan diversas funciones relacionadas con el SMOR (Semba y Fibinger, 1992; Shiromani, 1992).

Se ha determinado que la actividad unitaria de las células del locus coeruleus y del rafé dorsal presentan una frecuencia de disparo máxima durante la vigilia, que disminuye durante SOL, desapareciendo durante el SMOR (McGinty y Harper 1976). Otra estructura importante es el bulbo raquídeo que tiene dos núcleos que participan en la estimulación eléctrica para que se de la atonía muscular en SMOR, estos núcleos son el magnocelular y el paramediano, las neuronas de ambos núcleos proyectan sus fibras axonales por el tracto retículo-espinal ventrolateral hacia diferentes niveles de la médula ósea donde hacen sinapsis con interneuronas lo que induce la atonía muscular (Chase y Morales, 1994). Los movimientos oculares rápidos generados en la fase de SMOR son generados por del tronco cerebral, especialmente en la formación retícular pontina (FRP) (Gottesmann, 1997).

El sueño ejecuta importantes efectos moduladores sobre la mayoría de los componentes del sistema endocrino e inmune, desde las hormonas del eje hipotálamo-hipófisis-adrenal (HHA) como la hormona del crecimiento $(\mathrm{GH})$, prolactina y cortisol, hasta hormonas que regulan el balance de electrolitos y agua así como el - 16 - 
metabolismo de lípidos y carbohidratos. Existen moléculas como grelina, leptina, factor liberador de corticotropina (CRF) y diversas citocinas, que pueden tener influencia sobre el sueño y por tanto pueden ser considerados como "factores de sueño" (Weikel, 2003). Por ejemplo, se sabe que existen vías bidireccionales de comunicación entre el cerebro y el sistema inmune-endocrino, que son capaces de modular la defensa del huésped y los mecanismos del sueño (Opp, 2005).

De las citocinas estudiadas hasta ahora, la evidencia indica que algunas interleucinas como IL-6 e IL-1 $\beta$, están involucrados en la regulación del sueño (Majde, 2005). Pues IL-1 $\beta$ altera directamente los patrones de descarga de las neuronas en los circuitos del hipotálamo y del tronco cerebral implicados en la regulación del ciclo sueño-vigilia. En la rata, la administración de IL-1 $\beta$ aumenta el SOL y en los seres humanos el patrón circadiano de liberación de la IL-6 coincide con el de sueño/somnolencia y se eleva en los trastornos que presentan hipersomnolencia diurna como la narcolepsia y la apnea obstructiva crónica de sueño (SAOS) por sus siglas en inglés (Vgontzas, 2005). Además, la secreción de esta citocina es estimulada por la pérdida total o parcial del sueño que se refleja en el aumento de la somnolencia que experimentan los individuos privados de sueño. Se ha sugerido que la IL-6 es un mediador de la somnolencia y su patrón circadiano refleja la presión homeostática para dormir. Diversos reportes indican que la privación parcial de sueño (PPS) a corto plazo aumenta los niveles plasmáticos de marcadores de inflamación sistémica como TNF- $\alpha$ e IL-1 $\beta$ por células mononucleares de sangre periférica (Uthgenannt, 1995). La secreción de IL-6 es estimulada por la pérdida aguda, total o parcial del sueño (Vgontzas, 2005). Esto resulta interesante porque estos factores se relacionan con trastornos metabólicos como la diabetes y la obesidad (Mullington, 2010). 


\subsubsection{Funciones generales del sueño}

El hecho de pasar aproximadamente ocho horas diarias dormidos, que es la tercera parte de nuestra vida, sugiere que el sueño debe tener una función fisiológica muy importante. De manera similar a los humanos, todos los animales muestran ciclos de reposo conductual con duración variable, la fase de reposo podría ser considerada como condición comparable a nuestro sueño (Horne, 2002). Las hipótesis sobre la función del sueño son numerosas y muchas de ellas lo explican como un proceso homeostático.

Algunas de las hipótesis se centran en diferentes aspectos de la homeostasis como la restauración tisular, el balance energético, la termorregulación, la desintoxicación y la función inmune (Walker 1980).

La hipótesis de restauración ha sido desarrollada por Benington y Heller en 1995, y sugiere que el sueño es un estado que permite la reposición de las reservas de glucógeno en el cerebro, lo cual sirven como un importante amortiguador energético que sostiene la actividad neuronal durante la vigilia (Gruetter, 2003).

La fatiga (sensación de cansancio o falta de energía) es una condición natural tras un largo período de vigilia y actividad, la esencia de un sueño reparador, significa que una persona sana siente la ausencia de fatiga después de despertar. La pérdida crónica de sueño se asocia con somnolencia excesiva (sensación de amplio deseo de dormir, con una tendencia casi inevitable a quedarse dormido) y disminución del rendimiento psicomotor. También se pueden afectar el estado de ánimo, funciones autónomas e inmunes (Malik, 2005). Los patrones de sueño anormal como sueño de corta duración, insomnio, retraso o avance de alguna fase de sueño, se asocian con un mayor riesgo de padecer problemas de salud física y mental e inclusive incrementa la mortalidad (Kripke, 2002). Esta asociación identifica los aspectos cuantitativos y cualitativos de sueño como esenciales para la restauración del cuerpo y la mente. Una de las hipótesis al respecto es que el sueño tiene una importante 
contribución en la plasticidad del cerebro y los procesos de aprendizaje y memoria (Peigneux, 2001).

\subsubsection{Funciones del sueño MOR}

El sueño MOR es la fase del dormir en la que se presentan nuestros sueños más vívidos y ha inspirado a una multitud de teorías funcionales. La identificación de los "estados de sueño" como procesos fisiológicos periódicos durante el dormir ha fomentado la incorporación de ideas fisiológicas y psicológicas a las teorías más místicas de nuestros antepasados. EI SMOR es «paradójico» en el sentido de que a pesar que un animal en esta fase está conductualmente dormido, se observa una alta actividad cerebral tanto metabólica como neuronal, la respiración y el ritmo cardíaco en esta etapa son variables, se producen movimientos rápidos de los ojos y espasmos en las extremidades, en los machos se suelen presentar erecciones peneanas (Siegel, 2005; Nielsen, 2005). Estos fenómenos y los sueños vívidos que los seres humanos informan al despertar del SMOR han hecho a las funciones de esta fase, particularmente misteriosas e intrigantes. A pesar de la inmovilidad conductual y la reducción en la tasa metabólica corporal (en relación con la mantenida en la vigilia activa), parece existir una necesidad de pasar de sueño SOL a SMOR, incluso cuando en el primero existe una reducción en la actividad cerebral metabólica y una mayor eficiencia de recuperación y ahorro de energía que en el SMOR (Nielsen, 2005).

La idea de que el SMOR o el SOL sean 'absolutamente necesarios' para la consolidación de la memoria ha recibido mucha atención, diferentes reportes, en animales y humanos, han indicado que ambas fases de sueño son necesarias para cumplir funciones relacionadas con la memoria y aprendizaje, se sabe que el SOL es necesario en el proceso de aprendizaje, mientras que el SMOR es el responsable de la consolidación de la memoria a largo plazo. Sin embargo, se han propuesto otras teorías de la función del SMOR que incluyen: la hipótesis del procesamiento de la 
información, participación en la síntesis de proteínas, la promoción del crecimiento neuronal, entre otras, cada una de ellas sustentadas a través de algunos estudios de PS tanto en animales como en humanos (Siegel, 2005).

\subsection{Privación de sueño}

La PS se define como una falta del dormir durante un cierto periodo de tiempo, así como un desfase de la hora de dormir. Las causas más comunes de la PS se relacionan con el estilo de vida contemporáneo y factores laborales, por lo que esta afección daña a un número considerable de personas a nivel mundial (Bonnet, 2001). Se ha considerado a la privación parcial crónica de sueño (PPCS) una consecuencia de la restricción voluntaria de la hora de acostarse como una enfermedad endémica de la sociedad moderna (Parish, 2007).

De manera experimental, la deficiencia del sueño, puede lograrse con una privación total de sueño (PTS), lo que implica que se deje de dormir completamente durante 24 h, cuando no se concilia el sueño de manera continua o se duermen menos horas de las habituales es considerada como una privación parcial de sueño (PPS) y cuando se impide al individuo presentar alguna fase específica del sueño, se define como privación selectiva de sueño (PSS), tal es el caso de la PSMOR. Los primeros experimentos en humanos determinaron que la PSMOR a través de la técnica de mantener la vigilia por diversos estímulos, resultó en un constante intento de los sujetos para entrar al SMOR. Se ha propuesto que la PS actúa para desinhibir varias conductas como la agresividad, el consumo de alimento y la conducta sexual. Y se han observado de manera experimental en ratas con PSMOR cambios conductuales como agresividad, excitabilidad e incremento en el apetito (Hicks, 1979). 


\subsubsection{Métodos para PSMOR en animales}

La PS en los roedores, se ha utilizado con la finalidad de estudiar la función del sueño, sus etapas y los mecanismos biológicos que subyacen a los efectos de la PS. Los estudios de PS en animales difieren metodológicamente de los estudios en humanos. Diversas técnicas han sido desarrolladas para mantener a los animales despiertos o privarlos de una etapa especifica de sueño (predominantemente de SMOR). Algunas técnicas experimentales de PS utilizadas en animales han sido las siguientes:

\section{a) Privación manual (Gentle handling)}

Durante el período de PS, los animales y registros polisomnográficos son vigilados continuamente, cuando el animal muestra señales electrofisiológicas de sueño o asume una postura conductual se le despierta con una señal acústica y si es necesario se acompaña de estímulos físicos (Franken, 1991).

Esta técnica se utiliza para la PTS, como para la PSMOR y privación de SOL (PSOL) aunque para este último se requiere de la polisomnografía para vigilar la fase de sueño específica del animal.

b) Método de plataforma única o del florero invertido

Desarrollado por Jouvet en 1964 con el objetivo de suprimir el SMOR. El método es muy simple, se basa en una característica típica del SMOR, la atonía muscular. Durante el período de PS, el animal se coloca en la base de un florero invertido que sirve de plataforma, el diámetro de la plataforma es pequeño en relación al tamaño del animal. La plataforma se sumerge en una tina con agua hasta $1 \mathrm{~cm}$ de altura. El animal descansa en la plataforma e incluso presenta SOL. Pero cuando el animal entra a la fase de SMOR, la atonía muscular y la pérdida de balance hace que toque el agua y despierte. Este fue uno de los primeros métodos de PSMOR desarrollados, fue utilizado primero en gatos (Jouvet, 1964) y al siguiente año fue modificado para roedores (Cohen, 1965). 
c) Método de plataformas múltiples (MPM)

Este método es similar al anterior solo que existen varias plataformas para que el animal pueda desplazarse y se evite la restricción de movimiento a la que se le obliga cuando solamente hay una plataforma (Coenen,1985). Desafortunadamente para todos estos métodos, ha sido difícil aislar los efectos de la pérdida de SMOR de los del estrés fisiológico y de otros efectos secundarios inherentes a las propias técnicas de PSMOR. Estudios en animales indican que la PS activa la respuesta de estrés y el HHA, lo que genera liberación de hormona adrenocorticotropica (ACTH) y corticosteroides. Es sabido que tanto el estrés inducido por inmovilidad, restricción del movimiento o aislamiento social, así como la administración exógena de estas hormonas alteran diversos componentes del ciclo sueño-vigilia por lo que las técnicas de PSMOR no pueden evitar afectar per se a alguno de estos componentes (Suchecki y Tufik, 2000; Suchecki 2002; Vázquez, 2000; 2001). Sin embargo se ha observado que el grado de activación del HHA depende de la cantidad de estrés involucrado en el método de PS. Así con técnicas más estresantes como la de plataforma única, los animales presentan una importante activación del HHA (Patchev, 1991) mientras que la locomoción forzada y la privación manual son menos estresantes porque la activación del HHA es menor (Meerlo, 2002). En general, el MPM consiste en colocar un grupo de 8 a 10 ratas en el interior de una caja de acrílico con 14 plataformas circulares de $6.5 \mathrm{~cm}$ de diámetro y 3 centímetros de altura, la caja de acrílico contiene agua con una profundidad de $1 \mathrm{~cm}$. Este método reduce el factor de estrés por manipulación, aislamiento, inmovilidad o restricción del movimiento inducido por los otras técnicas arriba mencionadas, evaluado a partir de los niveles de corticosterona en la rata (Suchecki, 2000; Suchecki \& Tufik, 2000; Suchecki 2002). Por estas ventajas, este es el método elegido para utilizar en el presente proyecto. 


\subsubsection{PS e impacto en la calidad de vida}

Los seres humanos nos encontramos cada vez más expuestos a un deterioro en la calidad de nuestro sueño, esta afección daña a un número considerable de personas (Bonnet, 2001). En 1960, la American Cancer Society, realizó un estudio en adultos que mostró que sus tiempos de sueño eran entre 8.0 y 8.9 horas (Kripke, 1979). En promedio, la mayoría de los adultos necesitan dormir cada noche entre 7 y 9 hrs. para sentirse alertas y bien descansados, en adolescentes y niños en edad escolar el promedio oscila alrededor de $9 \mathrm{~h}$ y el de niños en edad preescolar entre 10 y $11 \mathrm{hrs}$. (Parish, 2007). En los últimos 40 años, la duración de sueño de los americanos ha disminuido en 1.5 a 2 hrs (Kristiansen, 2005). La proporción de adultos jóvenes que duermen menos de 7 h/día ha incrementado del $15.6 \%$ en 1960 a un $37.1 \%$ en 2002 (Parish, 2007). Desde hace varios años gran parte de la población mundial duerme en promedio solamente de 5 a 6 hrs por noche (Jean-Louis, 2000). La reducción crónica del tiempo de sueño o la fragmentación del mismo, puede ocasionar severas consecuencias que se comparan a las que se presentan en la privación de sueño aguda (PSA), lo que en particular se refiere a las funciones cognitivas, la atención y la memoria. Se ha visto que la falta de sueño afecta negativamente la capacidad de realizar tareas cognitivas que se cree se debe a un descenso general en el funcionamiento cognitivo (Ratcliff, 2009), Los datos epidemiológicos muestran una asociación entre la corta duración de sueño y los hábitos alimenticios irregulares (Imaki, 2002). Más de 65 artículos publicados han demostrado una asociación entre la disminución en las horas de sueño (menos de 6h por noche) y el incremento de la prevalencia de obesidad y/o el índice de masa corporal (IMC)(Jennings, 2007). Numerosos estudios de PST en ratas han identificado importantes procesos fisiopatológicos, que incluyen un incremento de gasto total de energía diaria (Ayas, 2003) y una marcada hiperfagia (Rechtschaffen, 1995).

A nivel patológico, los trastornos del sueño que afectan a cerca de $1 / 3$ de la población, se han relacionado con el síndrome metabólico (SM) (Ettaro, 2004), lo que 
sugiere que la falta de sueño crónica puede desempeñar un papel importante en el desarrollo de patologías como obesidad, diabetes e hipertensión (National Center for Health Statistics, 2005). Sin embargo no queda claro si la falta de sueño a corto plazo en humanos es de importancia clínica debido a que el peso ganado es mínimo.

\subsection{Generalidades del metabolismo}

El metabolismo energético se refiere a la serie de reacciones que almacenan y consumen combustibles para cubrir las necesidades energéticas del organismo. Los lípidos y los carbohidratos están considerados dentro de los cuatro mayores grupos de biomoléculas, los cuales sirven como combustible y reservas de energía principalmente. La glucosa es uno de los carbohidratos esenciales para la vida celular, los niveles sanguíneos de glucosa se encuentran altamente regulados por diferentes mecanismos, en este sentido la tolerancia a la glucosa (TG) se refiere a la capacidad del organismo de metabolizar la glucosa exógena y volver al estado de glucemia basal, de manera clínica esto es evaluado a partir de la prueba de tolerancia a la glucosa oral (PTGO), la TG depende fundamentalmente de la capacidad que tienen las células $\beta$ - pancreáticas para la liberación de insulina, de este modo, la resistencia a la insulina se produce cuando se necesitan mayores cantidades de insulina para reducir los niveles de glucosa en sangre (Van Cauter, 1997).

Una variedad de mecanismos que intervienen para mantener los niveles de glucosa durante el ayuno nocturno se asocia al sueño, pues en la primera mitad de la noche el metabolismo de la glucosa es más lento, predominantemente durante el SOL, asociado a una marcada reducción de captación de glucosa cerebral (Nofzinger, 2002) y durante la segunda mitad de la noche estos efectos se revierten (Van Cauter, 1991). 
Curiosamente para mantener el peso y composición corporal constantes se necesita del equilibrio entre el aporte y la utilización metabólica de los macronutrientes de la dieta. El organismo parece dar mayor prioridad al ajuste de la oxidación de glucosa y aminoácidos con relación a su ingesta, que al mantenimiento del balance de lípidos. El sistema de autorregulación homeostática en el balance lipídico es poco eficiente, siendo que la capacidad de almacenamiento de reservas energéticas en el tejido adiposo prácticamente es ilimitada. La ingesta excesiva de grasa es uno de los factores que frecuentemente más se asocian con la elevada incidencia de obesidad. En los seres humanos, muchos aspectos del metabolismo responden a los ciclos circadianos, incluyendo el metabolismo de la glucosa (Van Cauter,1997).

Numerosos reportes han indicado que las personas cuyo trabajo consiste en alternar turnos tienen una mayor incidencia de DT2 de obesidad, y eventos cardiovasculares (Spiegel, 2009).

En la población general, algunos estudios observacionales han encontrado que la PS corta, la PTS y la mala calidad del sueño se asocian con hipoleptinemia, aumento del apetito y obesidad (Taheri, 2004). Un estudio mostró que la duración del sueño se correlaciona con la magnitud de la pérdida de peso en forma de grasa en respuesta a la restricción calórica, el disminuir la cantidad de horas de sueño parece tener relación con la dificultad para perder grasa (Nedeltcheva, 2010).

\subsubsection{Regulación hormonal del metabolismo.}

El apetito y el metabolismo energético son regulados por una red de interacción de señales metabólicas, hormonales y neuronales. Algunas de las hormonas importantes en la regulación de los carbohidratos y las grasas son la insulina, la grelina y la leptina. La leptina es una hormona que entre muchas otras funciones inhibe el apetito, mientras que la grelina tiene el efecto contrario. El tejido adiposo es el encargado de producir la leptina, así como muchas otras moléculas, tal es el caso de las citocinas que al ser producidas en el tejido adiposo se conocen como 
adipocinas. Entre las adipocinas se encuentran la misma leptina, adiponectina, TNFa, IL-6, y resistina (Matsuzawa, 2006). Estas estimulan la secreción de factores que tienen un papel importante (local, periférico y central) en una variedad de procesos fisiológicos incluyendo la asimilación de alimento, balance energético, acción de insulina, metabolismo de lípidos y procesos homeostáticos (Matsuzawa, 2006).

Insulina

La insulina está formada por dos cadenas polipeptídicas de 30 y 21 aminoácidos unidas por puentes disulfuro, esta se sintetiza en los islotes de Langerhans, en particular en la célula $\beta$ pancreática. Las funciones de la insulina son muy variadas, aunque las más conocidas se relacionan con el metabolismo de los carbohidratos, pero no son de menor importancia las que ejerce sobre el metabolismo de lípidos. En general, la insulina es una hormona que estimula los procesos anabólicos e inhibe los catabólicos. A corto plazo aumenta la oferta de sustratos en el interior celular para el almacenamiento de energía y a medio plazo provoca un incremento de las actividades enzimáticas relacionadas con la formación de reservas energéticas. En el metabolismo de los carbohidratos, la insulina aumenta el transporte de glucosa a través de la membrana plasmática de las células en la mayoría de los tejidos, excepto en el cerebro (excluyendo el centro de la saciedad hipotalámico), los túbulos renales, la mucosa intestinal, las propias células $\beta$ pancreáticas y los eritrocitos. Los efectos de la insulina sobre el metabolismo de los lípidos se observan en periodos más largos que los que tienen lugar sobre los glúcidos. La insulina favorece el transporte de los ácidos grasos procedentes de los quilomicrones y las lipoproteínas liberadas del hígado así como su captación por la célula adiposa para ser almacenados. Finalmente, la insulina tiene también una importante acción inhibidora sobre la lipasa del tejido adiposo sensible a esta hormona, impidiendo que se liberen ácidos grasos a la sangre y sean transportados a otros tejidos. Cuando la insulina disminuye su capacidad para ejercer sus acciones biológicas en tejidos diana típicos como el músculo esquelético, el hígado o el tejido adiposo se habla de una resistencia a la insulina $(\mathrm{RI})$. Actualmente se considera que la $\mathrm{RI}$ de manera crónica 
o mantenida es la base común de numerosas enfermedades metabólicas como la DT2, obesidad y dislipidemias (componentes del SM) y enfermedad cardiovascular.

\section{Grelina}

Es una hormona peptídica de 28 aminoácidos sintetizada fundamentalmente por células del fundus, la parte proximal del estómago, y por las células $\varepsilon$ de los islotes de Langerhans pancreáticos, pero también en el núcleo arcuato hipotalámico, hipófisis y pulmón. La grelina es ligando natural del receptor de secretagogo de la hormona de crecimiento $(\mathrm{GH})$, además de estimular la síntesis de la $\mathrm{GH}$, favorece la regulación del metabolismo energético, la administración a roedores induce un incremento de peso corporal y adiposidad, además de inclinar el balance energético hacia el almacenamiento de energía (Van der Levy, 2004). La grelina fue descubierta en la leche materna (Aydin, 2006). Así mismo se observó una relación negativa entre la concentración de la grelina y el incremento del peso infantil, lo que sugiere que en niños sanos puede desempeñar un papel importante en la regulación del peso corporal. (Savino, 2005). El perfil de los niveles de grelina en $24 \mathrm{~h}$ muestra un incremento en fase nocturna, sin embargo los niveles de grelina tienden a disminuir después de la segunda mitad del periodo de sueño a pasar de mantenerse la condición de ayuno (Dzaja, 2004).

\section{Leptina}

Es una hormona de 167 aminoácidos, que participa en la regulación de la ingesta de alimentos y el peso corporal, con una función anorexigénica (Graaf, 2004). Esta hormona es sintetizada principalmente en el tejido adiposo y liberada al torrente sanguíneo de manera proporcional con la cantidad de masa grasa corporal, lo que ocasiona que en los adultos la concentración plasmática de la leptina tenga una relación directa con la masa de grasa corporal (Considine, 1996). En condiciones normales, el perfil de los niveles plasmáticos de leptina durante las $24 \mathrm{~h}$ revela que existe una elevación de la misma en alimentación parenteral nocturna (Graaf, 2004). 


\section{Citocinas}

Se ha observado que existe una relación importante entre el sueño y la inflamación sistémica pues algunas citocinas pro-inflamatorias, especialmente IL-1 $\beta$ y TNFa han sido evaluadas en estudios experimentales y se ha sugerido que cumplen con criterios para ser consideradas sustancias reguladoras del sueño. (Krueger, 2007). Se ha mencionado también que en personas cuyas condiciones de sueño son normales, las citocinas pro-inflamatorias (IL-1 $\beta$ y TNF $\alpha$ ) están implicadas en la regulación fisiológica del sueño con un factor de secreción circadiano. (Vgontzas y Pejovic, 2007a). Dándose amplio reconocimiento del papel que juega la IL-6 en el sueño, pues la disminución en su secreción se asocia con un sueño de mayor calidad por la noche y con el buen estado de vigilia al día siguiente (Vgontzas y Papanicolaou, 1999), condición que se relaciona con las evidencias existentes de que su administración en humanos se asocia con una somnolencia excesiva y fatiga diurna. (Mastorakos, 1993).

\subsubsection{Trastornos del metabolismo}

El SM representa una combinación de factores determinantes de riesgo cardiometabólico como son la obesidad, RI, intolerancia a la glucosa (IG), dislipidemia, hígado graso no alcohólico y la hipertensión arterial (HA). El SM está incrementándose rápidamente en todo el mundo como consecuencia de una epidemia de obesidad y cuyo resultado tendrá impacto en la incidencia mundial de enfermedades cardiovasculares y en el desarrollo de DT2. En 1988, Reaven postuló que la RI es causante de la IG y que el incremento en las lipoproteínas de muy baja densidad (VLDL) así como la disminución de las lipoproteínas de alta densidad (HDL), llevan a la hiperinsulinemia y más tarde a la HA (Reaven, 1988). La acumulación de lípidos puede afectar directamente a las vías a través de la liberación de factores inmunológicos, la ingesta de grasas en la dieta también puede influir 
directamente en las vías inflamatorias. Algunos estudios han demostrado que la alta ingesta de grasas en la dieta se asocia con el estrés oxidante y la activación del factor nuclear de transcripción KB (NFkB) con efecto pro- inflamatorio (Aljada, 2002). Por el contrario una dieta rica en frutas y fibra no induce inflamación en comparación a una dieta alta en grasas, incluso si tiene la misma proporción de calorías (Dandona, 2005). La obesidad visceral, se caracteriza por la asociación de grasa con órganos internos, y parece ser el componente clave que determina la enfermedad cardiometabólica (Wajchenberg, 2000). Se sabe que el tejido adiposo es un regulador del balance de energía, y juega un papel activo en el almacenamiento de lípidos, así como la síntesis y secreción de productos endócrinos implicados con las complicaciones asociadas a la obesidad (Trayhurn, 2004).

Las complicaciones vasculares características de la DT2 y obesidad, se asocian con la secreción alterada de marcadores inflamatorios como TNFa, IL-6, proteína C reactiva (P-CR) y resistina, modificando también los niveles de leptina, que contribuyen al daño vascular y a la RI (Schultes, 2005). Estas alteraciones afectan a los componentes de la regulación de la glucosa, del apetito o modifican la producción de adipocinas inflamatorias (Ranjabaran, 2009). TNFa e IL-6 son factores que están sobre expresados en los adipocitos por una estimulación pro-inflamatoria. Aunque TNFa actúa principalmente a nivel local y no está en niveles elevados en la circulación en condiciones metabólicamente normales. En el caso de los adipocitos viscerales, la IL-6 es liberada en la vena porta donde se desvía directamente en el hígado. Mientras que TNF- $\alpha$ parece actuar a nivel local en el tejido adiposo que influye en los niveles de otras adipocinas como la adiponectina (Guerre-Millo, 2004). 


\subsubsection{Relación sueño- metabolismo}

Una variedad de mecanismos que intervienen para mantener los niveles de glucosa durante el ayuno nocturno, se asocian al sueño. Se sabe que las alteraciones derivadas de una PSA, se corrigen fácilmente con el dormir, por ende la pérdida de sueño de manera crónica puede tener efectos negativos sobre el metabolismo de la glucosa. Se ha visto que la PSA (2h/noche) por 7 días se asocia con mayores niveles de citocinas pro-inflamatorias, así como con un proceso inflamatorio en bajo grado, condición que predispone a la $\mathrm{RI}$ en el proceso patológico de la diabetes (Vgontzas, 2004). Un estudio realizado en E.U.A con hombres sin referencia de diabetes, asoció la duración de 6 o menos h/noche, con el riesgo de desarrollar DT2 después de ajustar variables tales como la edad, HA, tabaquismo y circunferencia de la cintura (Yaggi, 2006; Gallup Organization, 1995). Al parecer, con el paso del tiempo la reducción de horas de sueño, se da de forma cada vez mas frecuente. Hasta hace poco tiempo más del $30 \%$ de hombres y mujeres adultos entre los 30 y 64 años de edad informan dormir menos de 6 h/noche (National Center for Health Statistics, 2005).

La disminución de sueño en Estados Unidos ha ocurrido durante el mismo periodo de tiempo en que se a incrementado la prevalencia de obesidad y DT2. La obesidad es en sí un factor de riesgo importante para el desarrollo de la DT2, pero los datos indican que el sueño de corta duración puede afectar el metabolismo de la glucosa e incrementar el riesgo a padecer DT2, la restricción en las horas de sueño puede afectar el equilibrio energético dando como resultado un incremento de peso corporal debido al incremento del apetito, más tiempo disponible para comer y una disminución del gasto energético (Punjabi, 2004). En México la Encuesta Nacional de Salud 2000, mostró una prevalencia de obesidad del 24\% moderada en la población mayor de 20 años (Velásquez, 2002). 
Aunque no existe una estimación certera de la prevalencia del SM en la población mexicana, el incremento en el sobrepeso/obesidad probablemente se acompaña de un incremento de tal síndrome, lo que coincide con la DT2 (Escobedo, 1994).

Resultados epidemiológicos indican que dormir $5 \mathrm{~h}$ o menos aumenta de forma significativa las probabilidades de padecer DT2, en comparación con las personas que duermen $7 \mathrm{~h}$ (Tuomilehto, 2007). Se reportó que: "las principales perturbaciones metabólicas que acompañan la PS son la RI y la disminución de la TG" (Van Helder, 2003) Estas alteraciones fueron observadas cuando se producía una PTS durante más de $40 \mathrm{~h}$. Un número creciente de estudios epidemiológicos han asociado a la duración del sueño con la DT2 y el IMC. Un informe español reportó que dormir 6h o menos por día aumenta el riesgo de obesidad después de excluir la influencia del género, la edad, entre otros factores (Kripke, 1979). Este grupo también encontró un IMC más alto para aquellos sujetos que dormían menos de 9h al día. Finalmente, un estudio en 924 adultos realizado en E.U.A encontró que los participantes con sobrepeso y obesidad reportaron menos tiempo de sueño que los sujetos con un IMC normal (Young, 1993). Asociaciones similares se han encontrado también en adolescentes y niños.

En un estudio de PS por 5 días, la ingesta de alimento incremento cerca de un 29\% (Koban, 2008). En otro estudio se observó un considerable incremento del apetito en personas a las que se les permitió dormir solo $4 \mathrm{~h} /$ noche, atribuible a la concentración de leptina, al mismo tiempo se presenta también un nivel mayor de grelina (Spiegel, 2004). En resumen, varios estudios epidemiológicos han indicado que el acortamiento de sueño puede aumentar el riesgo de obesidad y DT2. 


\subsubsection{PSMOR y metabolismo}

Existe importante evidencia que ha demostrado que la privación prolongada de SMOR conduce a una reducción en la masa corporal, aumenta el metabolismo energético, altera los niveles de hormonas circulantes, induce pérdida de la integridad inmunológica, y otros desordenes (Everson, 1989).

La PSMOR en los roedores produce hiperfagia y un marcado aumento de la pérdida del calor corporal, lo que lleva a la pérdida de peso, aumento de la concentración plasmática de catecolaminas, hipotiroidismo, reducción de la temperatura corporal y deterioro de la apariencia física (Rechtschaffen, 2002) así como la reducción de los niveles de hormonas anabólicas (Everson, 2004) llevando a la muerte en un periodo aproximado a 5 semanas.

Por el contrario, la PTS conduce a la muerte en alrededor de 2 a 3 semanas, sin embargo la causa de la muerte ya sea por PTS o por PSMOR no está clara, pero al parecer esta asociada con el balance de energía, la hipotermia y el fallo del sistema inmune acompañado de septicemia (Eversen, 1997). Por otro lado, los niveles séricos de glucosa, triglicéridos y leptina disminuyen, mientras que los niveles de adiponectina no se alteran, y por su parte se incrementan los niveles de corticosterona hasta 5 veces los niveles basales. Debido a este último dato, que involucra una respuesta de estrés inducida probablemente por el método de PSMOR, es difícil la interpretación certera de los resultados (Rosa-Neto, 2010).

La PSMOR induce una respuesta inflamatoria con aumento de citocinas proinflamatorias (Shearer, 2001; Yehuda, 2009). $72 \mathrm{~h}$ de PSMOR incrementa los niveles séricos de TNFa, IL-6, IL-1 $\alpha$ e IL-1 $\beta$ en ratas. En humanos la PS incrementa los niveles de la P-CR e IL-6 (Patel, 2009). Además, un estudio demostró que la restricción del sueño en un $50 \%$ del tiempo durante 10 días, induce un aumento significativo en los niveles de IL-6 (Haack, 2002). La elevación crónica de proteínas inflamatorias puede contribuir a problemas de salud que incluyen problemas 
cardiovasculares, endocrinos, del estado de ánimo y trastornos del sueño (Frey, 2007).

Por otra parte, los sujetos con pérdida de sueño mostraron un aumento en la unión al ADN de NF-KB en las células mononucleares de sangre periférica (Irwin, 2008). Lo cual representa un evento clave en la actividad de este factor. La activación de NFKB se cree que contribuye a la fisiopatología de enfermedades como la DT2, enfermedad cardiovascular y la aterosclerosis (Bierhaus, 2003). También se ha observado que la PSMOR por $96 \mathrm{~h}$, por el método de florero invertido, eleva los niveles de IL- 6 en tejido adiposo retroperitoneal mientras que los niveles de TNF- $\alpha$ disminuyen en tejido adiposo mesentérico (Rosa Neto 2010).

Un par de estudios han examinado los niveles de leptina y grelina en humanos durante la PSA, las personas recibieron nutrición enteral continua y se observó que los niveles plasmáticos de leptina aumentaron ligeramente durante la PS nocturno y el nivel máximo se produjo después (Simon, 1998). El incremento nocturno de grelina es ligero pero de manera significativa durante la PSA en comparación con el grupo control (Dzaja, 2004). En conjunto, los estudios indican que la duración de sueño puede jugar un papel importante en la regulación de los niveles de leptina y grelina, el hambre y el apetito. Así mismo se sugiere que la pérdida de sueño puede conducir a un mayor consumo de alimento, esto de acuerdo a los reportes de ingesta alimenticia en humanos y roedores que se encuentran en PTS (Rechtschaffen, 1995). Sin embargo, los niveles de grelina y leptina no han sido evaluados luego de suspender la PSMOR.

Algunos otros hallazgos indican una relación más estrecha entre el sueño y el comportamiento del apetito y la alimentación, lo que hace creer que el SMOR puede desempeñar un papel complementario, aunque pequeño, pero fundamental en la regulación del balance energético así como en la organización de la conducta de la alimentación (Horne, 2002), aunque esto no ha sido comprendido aún. 


\section{JUSTIFICACIÓN}

El dormir puede ser afectado no solo por procesos patológicos, sino también por las presiones que ejercen el estilo de vida y las demandas sociales sobre los horarios del dormir y sobre nuestra vida en vigilia. Cuando se producen alteraciones en el sueño, sin importar la razón, las consecuencias sociales en términos de salud pueden llegar a ser graves. Actualmente, sólo hay un limitado reconocimiento de este hecho fundamental.

El sueño, como otros aspectos de la actividad humana, ha sido alterado por las revoluciones tecnológicas y sus acompañantes como la luz artificial y las nuevas tecnologías, etc. Desde hace cerca de un siglo, se han vuelto comunes las actividades laborales, económicas y sociales durante las $24 \mathrm{~h}$ del día y el tiempo asignado para dormir ha dado paso a una mayor productividad, diversión, etc. Ello ha generado acortamiento de nuestro tiempo de sueño y niveles deficientes de verdadera vigilia. Mientras en 1910 se dormía en promedio 9 h/noche, un siglo después dormimos en promedio $25 \%$ menos en todo el mundo y en particular en ciudades como el Distrito Federal. La reducción en la duración del dormir ha coincidido temporalmente con el incremento en la prevalencia de enfermedades metabólicas como la DT2, la obesidad y la HA. Sin embargo, estos estudios, al igual que los realizados en animales, en su mayoría solo muestran la correlación entre PS y DT2.

La naturaleza y la relación causa-efecto entre las consecuencias inducidas por la PS, en sus diferentes variantes, en particular la PSMOR sobre la aparición y el desarrollo de la DT2 es incierta y requiere ser explorada sistemáticamente con cierto grado de profundidad mediante diseños experimentales. En algunos casos solo se sugieren relaciones y nuevas hipótesis de acuerdo a los resultados, pero por desgracia muy pocas de estas líneas sugeridas ha sido corroboradas en subsecuentes trabajos o generaron nuevas líneas de investigación más allá de 
mencionar la participación de alguna de las sustancias en la regulación del sueño siempre a nivel cerebral, pero no de sus efectos a nivel del organismo. En menos casos se integraron y se correlacionaron con la aparición o agravamiento de algún problema de salud o patología específica. Aunado a esto los métodos de privación no son uniformes y hasta tiempos recientes se cuestionaron los efectos de factores intrínsecos a los procedimientos de PS como el estrés o el aislamiento.

En este sentido, cabe mencionar que es necesario evaluar los efectos de diferentes periodos de PSMOR sobre marcadores metabólicos e inflamatorios en ratas a través del MPM. Evaluándose también la respuesta del organismo ante la recuperación (periodo posterior a la PSMOR). Finalmente, el presente proyecto consiste en analizar por primera vez los posibles cambios que puedan inducir diferentes periodos de PSMOR, sobre los niveles de glucosa, los niveles de marcadores de inflamación (IL-6) y otros componentes metabólicos (grelina, leptina, triglicéridos, colesterol, VLDL, HDL y LDL en ratas.

\section{PREGUNTA DE INVESTIGACIÓN}

¿Puede la PSMOR alterar la PTGO, los niveles de lípidos, algunos marcadores de inflamación y concentraciones de corticosterona y en consecuencia ser un factor importante en la aparición de los trastornos englobados en el denominado SM, y dichas respuestas depender del tiempo de PSMOR?

\section{HIPÓTESIS.}

La PSMOR, inducirá modificaciones en el metabolismo de glucosa, lípidos y hormonas reguladoras así como alteraciones en el perfil inflamatorio, y estas dependerán del tiempo de PSMOR. 


\section{OBJETIVO.}

Evaluar el efecto de diferentes periodos de PSMOR sobre el metabolismo de glucosa, lípidos y hormonas, así como sobre el perfil inflamatorio en ratas.

\subsection{OBJETIVOS PARTICULARES.}

- Determinar el metabolismo de la glucosa a través de la PTGO en ratas con diferentes periodos de privación de SMOR, 1, 4 y 8 días y un periodo posterior de descanso de 20 días sin PSMOR luego de un periodo de PSMOR de 8 días.(8RPSMOR)

- Determinar el perfil lipídico (colesterol, triglicéridos, VLDL, HDL, LDL) en animales en diferentes periodos de PSMOR (1, 4 y 8 días) y $8 R P S M O R$

- Determinar la ganancia de peso y el consumo de alimento en ratas antes, durante y después de diferentes periodos de PSMOR (1, 4 y 8 días) y 8RPSMOR.

- Analizar la concentración serica de moléculas reguladoras del metabolismo: leptina, insulina, grelina, en animales sometidos a diferentes periodos de PSMOR (1, 4 y 8 días) y 8RPSMOR

- Determinar el efecto de diferentes periodos de PSMOR sobre el perfil inflamatorio establecidos a través de la evaluación de los niveles de citocina pro-inflamatoria: IL-6 en ratas. 


\section{DISEÑO EXPERIMENTAL}

\subsection{Modelo experimental}

Ratas macho de la cepa Wistar de 3 meses de edad (250-350 g), criados en el bioterio de la UAM-Iztapalapa, mantenidos bajo dieta básica para roedores (22\% de proteína, $5.5 \%$ de grasa, $3.9 \%$ de fibra, densidad energética $3.0 \mathrm{Kcal} / \mathrm{g}$ y $54 \%$ de calorías por carbohidratos) y en un ciclo luz- oscuridad 12-12 h. (9 am-9 pm). El manejo de los animales se realizó de acuerdo a los principios generales para el cuidado de animales de laboratorio y a la Norma Oficial Mexicana NOM-062-ZOO1999, revisada en el 2001. Los animales se asignaron a los siguientes grupos experimentales con $(n=5)$.

a) Ratas control (para cada grupo experimental)

b) Ratas sometidas a 1 día de PSMOR

c) Ratas sometidas a 4 días de PSMOR

d) Ratas sometidas a 8 días de PSMOR.

e) Ratas sometidas a 8 días de PSMOR con 20 días de recuperación.

Posteriormente a los animales se les realizó una PTGO, se cuantificaron niveles de triglicéridos, colesterol total, lipoproteínas (LDL, HDL y VLDL), IL-6, insulina, grelina y leptina, así como niveles de corticosterona (Todas las mediciones se realizaron al terminar la fase de luz, es decir a las 9am).

El grupo control fue mantenido en la caja de privación de sueño pero con aserrín, durante el mismo tiempo según el diseño de periodos de PSMOR.

La obtención de las muestras para la PTGO se realizo a partir de la punción de la vena caudal y para la determinación de los niveles séricos de las diferentes hormonas e IL-6, se utilizó la técnica de decapitación, se obtuvo la sangre en tubos vacutainer con activador de coagulación (calcio) y gel separador de suero (Becton, Dickinson and Company), posteriormente las muestras se centrifugaron 15 minutos a 
2500 rpm para obtener el suero y se realizaron alícuotas por animal para cada una de las determinaciones séricas. Las alícuotas fueron almacenadas a $-70^{\circ} \mathrm{C}$ hasta su análisis (para todos los casos, las muestras no excedieron los 3 meses de almacenamiento).

Todos los animales (incluyendo el grupo control) fueron manipulados durante 7 días previos a los procedimientos experimentales con el fin de habituarlos y evitar factores desencadenantes de estrés que pudieran confundir los resultados, esto consistió en su manipulación típica, punción de la vena caudal, administración intragástrica y alimentación en la caja de privación.

Se determinó el peso corporal desde el inicio de la PSMOR hasta la culminación de la misma con el uso de una balanza OHAUS con canastilla para roedores, así como en el periodo de recuperación posterior a 8PSMOR. El control de peso se realizó en condiciones estandarizadas de horario, esto posterior a la inicio de la fase oscura (9 a.m). Para determinar el peso corporal en el grupo de recuperación se dejo un plazo de 17 días, por lo que la recuperación en el experimento de peso corporal fue de 17 días.

\subsection{Método modificado de plataformas múltiples para PSMOR}

Los animales se sometieron a PSMOR por el método modificado de plataformas múltiples (para descripción detallada ver Sucheki \& Tufik, 2000). En general, este método consiste en colocar un grupo de 8 ratas en el interior de una caja de acrílico con 14 plataformas circulares de $6.5 \mathrm{~cm}$ de diámetro y $3 \mathrm{~cm}$ de altura, en la base de la caja de acrílico, se colocó agua con una profundidad de $1 \mathrm{~cm}$. Como se mencionó anteriormente este método reduce el factor de estrés por manipulación, aislamiento, inmovilidad o restricción de movimiento inducidos por los métodos habituales (Suchecki, 2000; Suchecki y Tufik, 2000; Suchecki, 2002). Al inicio de cada episodio de SMOR, los animales experimentan una pérdida de tono muscular y al tocar el agua se despiertan, lo que les priva selectivamente de SMOR. En todos los grupos 
de PSMOR, el alimento y el agua estuvieron disponibles ad libitum. Diariamente se tuvo control sobre la higiene de los animales, lavando el depósito de la caja con solución de extrán y colocando agua limpia a la caja. Luego de cada tratamiento los animales fueron llevados a sus cajas habituales para las evaluaciones respectivas.

\subsection{Evaluación de parámetros bioquímicos.}

Para la cuantificación de lípidos se utilizó una técnica enzimática y para su análisis un aparato automatizado: cardiocheck (polimer technology system Inc), se aplicó una muestra de sangre total en la tira reactiva (aproximadamente $80 \mu \mathrm{l}$ ), la muestra en el interior del aparato de análisis es separada en sus diferentes componentes lisando las células para favorecer la lectura de los lípidos. Los resultados obtenidos están basados en la lectura de la luz reflejada de la zona reactiva de la tira, después de adicionar la muestra, se experimenta un cambio de color proporcional a la concentración del parámetro a medir, el cambio de color es leído por el analizador utilizando fotometría de reflactancia, las reacciones enzimáticas utilizadas fueron las siguientes:

Colesterol: Los ésteres de colesterol son desdoblados a colesterol y ácido graso correspondiente con la enzima colesterol oxidasa, posteriormente en presencia de agua y oxígeno se convierte en colesterol-4-en-3-ona y peróxido de hidrógeno que en presencia de la enzima peroxidasa con 4-AAP y anilina disustituida forma el compuesto coloreado y agua.

HDL: la enzima colesterol esterasa separa el colesterol total en colesterol éster, colesterol y agua, más el ácido graso correspondiente que en presencia de la enzima peroxidasa se obtiene colesterol -4-en-3-ona y peróxido de hidrógeno, en adición a 4AAP, agua y anilina disistituida se forma el compuesto coloreado y agua.

Triglicéridos: a partir de la lipoproteín lipasa se obtiene triglicérido y 3 moléculas de agua más glicerol, así como 3 ácidos grasos que en presencia de la enzima glicerolcinasa se da la separación en glicerol y ATP glicerol-3PO $\mathrm{P}_{4}$ más ADP, que con 
la enzima glicerofosfato oxidasa se produce Dihidroxiacetona $-\mathrm{PO}_{4}$ que en presencia de peroxidasa se origina N,N-Anilina disustutiuda compuesto coloreado.

Para la determinación de LDL y VLDL, se usaron los valores obtenidos de colesterol total, triglicéridos y $\mathrm{HDL}$, con base en las siguientes fórmulas de Friedewald, como una forma indirecta de aproximación a los valores reales:

$\mathrm{LDL}=$ Colesterol total $-[($ Triglicéridos/5) $+\mathrm{HDL}]$

VLDL $=$ Triglicéridos $/ 5$

\subsection{Prueba de tolerancia a la glucosa oral.}

Una vez cumplido el correspondiente periodo de PSMOR todos los grupos fueron sometidos a un ayuno de $12 \mathrm{~h}$. (9pm - 9am). Una vez cumplido el periodo de ayuno, se tomó una muestra de glucosa basal por punción de la vena caudal, posteriormente se les administró por vía intragástrica una carga de dextrosa anhidra (2 mg/kg diluida en solución inyectable, Laboratorios Pisa S.A. de C.V. México). Se tomaron diferentes muestras en un aproximado de $20 \mu \mathrm{l}$ a los tiempo $(30,60,90$, 120, 150 minutos) mediante la misma punción previamente realizada para la glucosa basal, para la medición de la concentración de glucosa se usó un glucómetro automatizado que se basa en el método de la glucosa deshidrogenasa (Accu-chek, Performa. Roche). Utilizando tiras reactivas (KDK Corporation, Japón; para Bayer Corporation, Alemania). En presencia de la coenzima (PPQ), la enzima de la tira reactiva glucosa deshidrogenasa, convierte la glucosa de la muestra de sangre en gluconolactona, esta reacción crea una corriente eléctrica que el medidor traduce en un valor de glucemia. 


\subsection{Ensayo por inmuno-absorción ligado a enzimas (ELISA).}

La cuantificación de insulina, leptina, grelina, corticosterona e IL-6 se realizó en suero por la técnica de ELISA, con estuches comerciales (Thermo Scientific) para el caso de IL-6, (Millipore) para leptina, grelina e insulina, en el caso de la corticosterona fue evaluada por un kit para ELISA de la marca (ALPCO immnoassays) utilizando reactivos específicos para rata estipulados por cada Kit y siguiendo las indicaciones de los proveedores. Las placas de ELISA fueron leídas por el espectrofotómetro de prisma (Thermo Scientific, Multiskan GO) a las longitudes de onda indicadas por cada proveedor. Para la recuperación en los análisis hormonales y de citocinas se dejó un plazo de 20 días posteriores al mayor periodo de PSMOR que fue de 8 días.

\subsection{Análisis estadístico.}

Los resultados se presentan como media \pm error estándar de la media $(M \pm E E M)$. En todos los casos se realizó un análisis de varianza (ANOVA de una sola vía) para comparar el efecto de la PSMOR sobre el perfil lipídico, PTGO, IL-6, insulina, grelina, leptina y corticosterona. Se usaron las pruebas de Tukey para las pruebas de PTGO y perfil de lípidos y Newman Keuls para las pruebas de leptina, grelina, insulina e IL-6 para establecer las diferencias entre los grupos, en base a la capacidad de las pruebas y a la variabilidad de los datos obtenidos. En todos los casos se consideraron diferencia estadísticamente significativa si $p<0.05$. La totalidad de las pruebas estadísticas se efectuarán con el programa GB-STAT (Dynamic Microsystems, Inc.). Para observar la diferencia entre grupos se realizó un pool de controles, debido a que presentaron la misma respuesta para cada uno de los experimentos, por tanto para los controles $n=20$. 


\section{RESULTADOS}

\subsection{Efecto de la PSMOR sobre el peso corporal}

Por la importancia que refiere conocer el peso de los animales sometidos a diferentes periodos de PSMOR, en este experimento observamos la pérdida de peso corporal durante los 8 días de PSMOR y los 17 días posteriores de recuperación. Esto ocurre a pesar de que en condiciones basales (al inicio del estudio), los animales experimentales presentan un mayor peso el cual es incluso estadísticamente significativo en comparación con el grupo control (condición que se dió completamente al azar). Los animales con PSMOR pierden peso de manera paulatina, observándose un cambio importante a partir del día 4 de PSMOR $(p<0.01)$. Esta disminución de peso alcanza su máximo hasta 8 días de PSMOR $(p<0.0001)$, observándose una diferencia de peso de $90 \mathrm{~g}$ con respecto al peso inicial y una reducción cercana al $20 \%$ con respecto al grupo control.

Esta disminución se mantiene aún después de 4 días de recuperación de SMOR $(p<0.001)$, sin embargo, posterior a los 10 días de recuperación parecen aumentar de peso, pero no alcanzan su peso inicial aún después de trascurridos los 17 días de recuperación. 


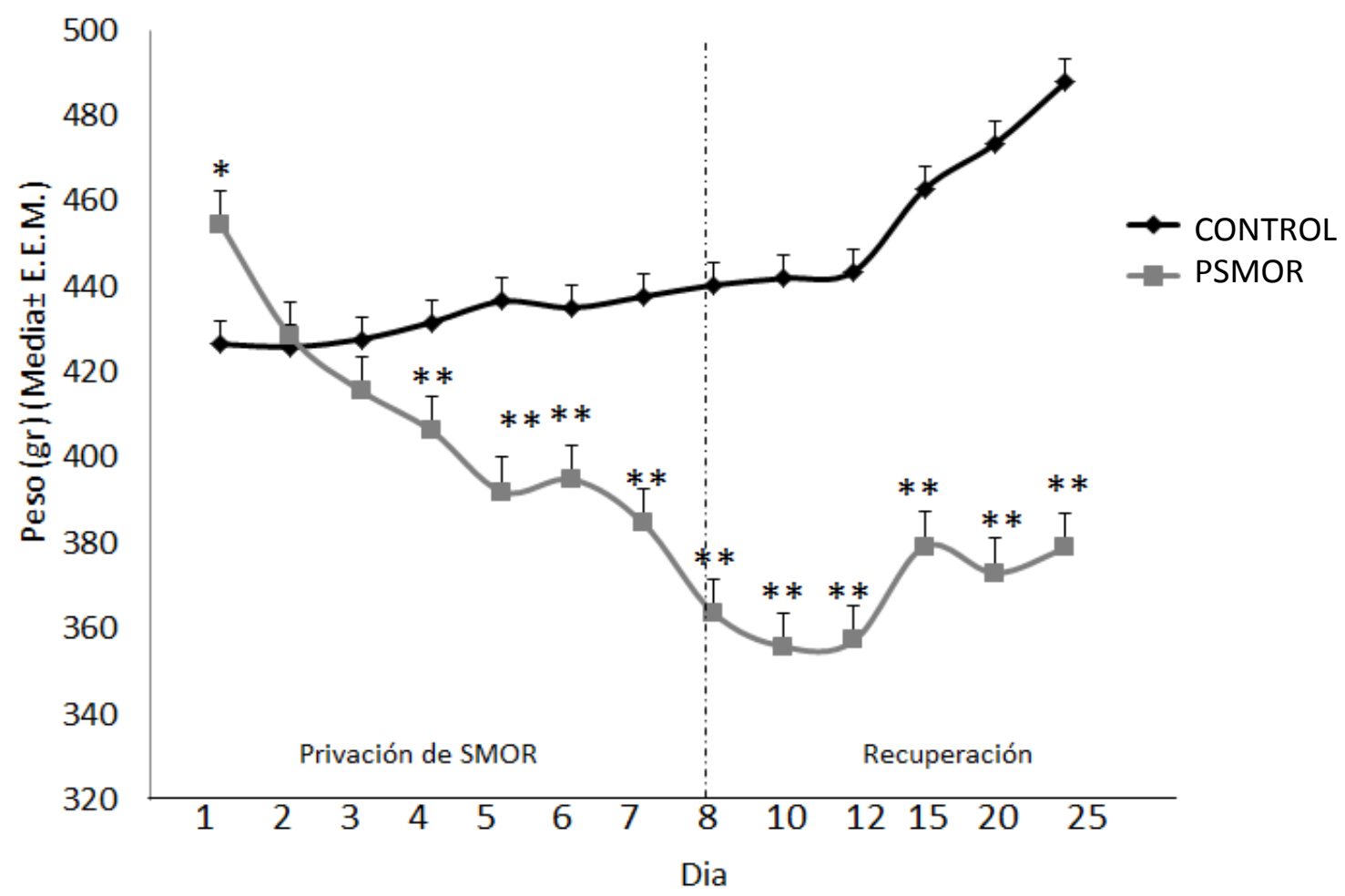

Figura 1. Efecto de la PSMOR y recuperación sobre el peso corporal $(\mathrm{g})$, cada punto representa la Media $\pm E E M$. Se observa una progresiva pérdida de peso corporal dependiente del tiempo de PSMOR, efecto que no se restablece luego de 17 días de recuperación. ANOVA seguida de Tukey, diferencias significativas con respecto al grupo control ${ }^{* *} p<0.01$ ${ }^{*} \mathrm{p}<0.05(n=5)$

\subsection{Efecto de la PSMOR sobre la PTGO}

El manejo de la glucosa por medio de la PTGO de los grupos con PSMOR y el grupo control se muestra en la siguiente figura. Se puede observar que la concentración basal de glucosa en los animales control se encuentra alrededor de los $90 \mathrm{mg} / \mathrm{dL}$, con un incremento máximo a $140 \mathrm{mg} / \mathrm{dL}$ después de la administración de dextrosa anhidra.

Todos los grupos sometidos a PSMOR presentan bajos niveles de glucosa en sangre al inicio de la prueba $(\mathrm{p}<0.0001)$. Los niveles de glucosa en sangre durante la PTGO en el grupo de 1 día de PSMOR se observan con una respuesta similar con respecto 
al grupo control, con pocas fluctuaciones, sin embargo el manejo de glucosa en el grupo de 4 días de PSMOR se observa con bajas concentraciones de glucosa antes y después de la administración de dextrosa anhidra ( 0 y 30 minutos), estas bajas concentraciones de glucosa se mantienen durante toda la PTGO en los animales con 8 días de PSMOR $(p<0.05)$. Un efecto inverso se observó después de 20 días de recuperación, pues los animales presentaron una tendencia a incrementar sus concentraciones de glucosa basal y un aumento estadísticamente significativo a los 30 minutos después de la administración de dextrosa anhidra $(p<0.01)$.

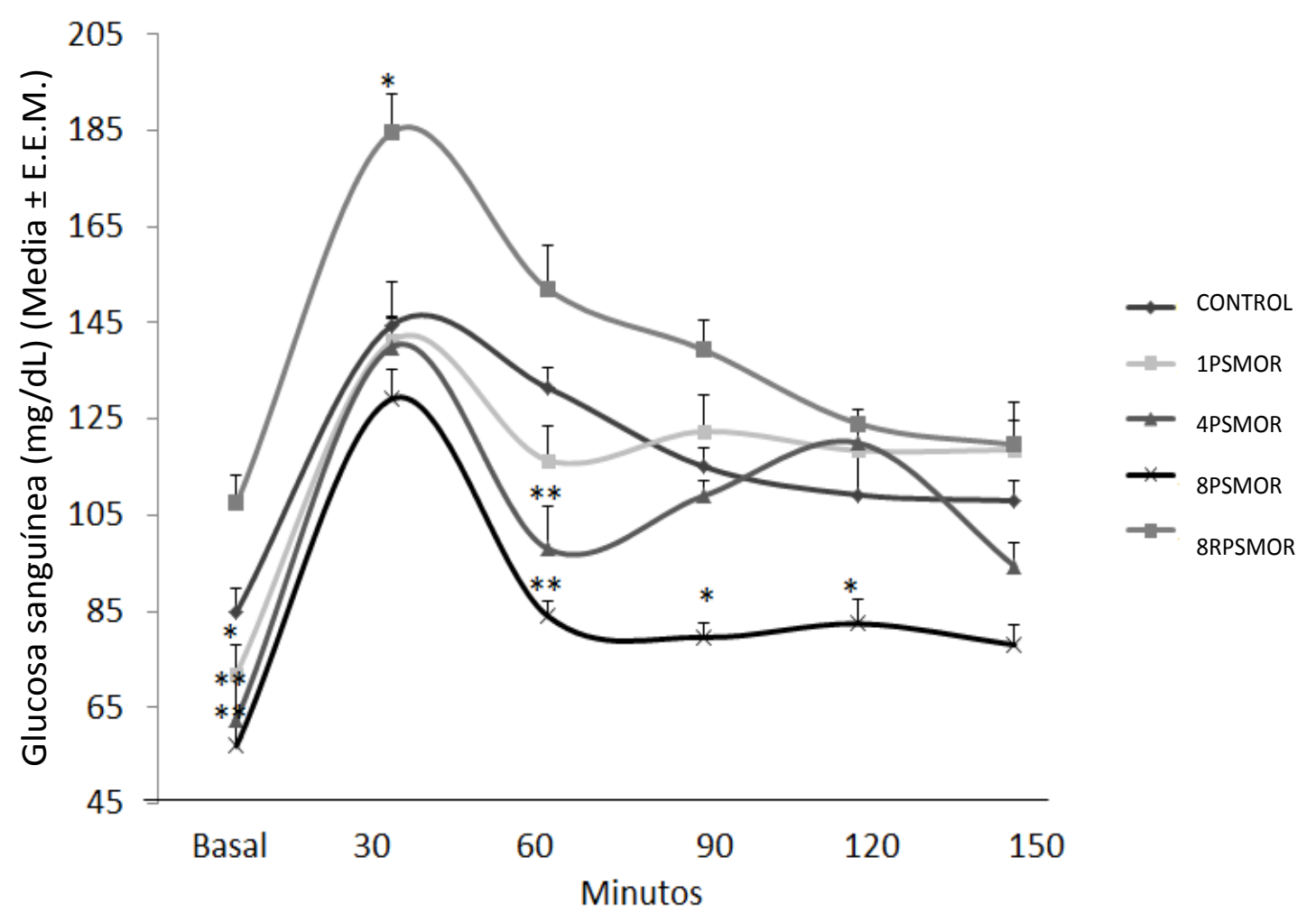

Figura 2. Efecto de diferentes periodos de PSMOR sobre la PTGO. La PSMOR induce una hipoglucemia en los diferentes periodos de PSMOR y esta hipoglucemia se mantiene en los diferentes tiempos evaluados mediante la PTGO, e incluso es mayor a los 8 días de PSMOR. Un aumento en las concentraciones de glucosa en el minuto 30 se observa después de 20 días de recuperación. $(n=5)$ Media $\pm E E M$, ANOVA seguida Tukey, diferencias significativas con respecto al grupo control ${ }^{* *} p<0.01{ }^{*} p<0.05$. 


\subsection{Efecto de la PSMOR sobre los niveles de insulina}

Los animales con PSMOR presentan una disminución en las concentraciones de insulina estadísticamente significativa desde el primer día de PSMOR $(p<0.05)$, una tendencia a disminuir se observa en el día 4 de PSMOR, haciéndose significativa nuevamente a los 8 días de PSMOR ( $p<0.0001)$, los niveles de insulina descienden drásticamente $(98 \%)$ a los 8 días de PSMOR $(0.0335 \mathrm{ng} / \mathrm{mL})$ en relación al grupo control $(2.734 \mathrm{ng} / \mathrm{mL})$, sin embargo esta condición parece restablecerse a los 20 días de recuperación.

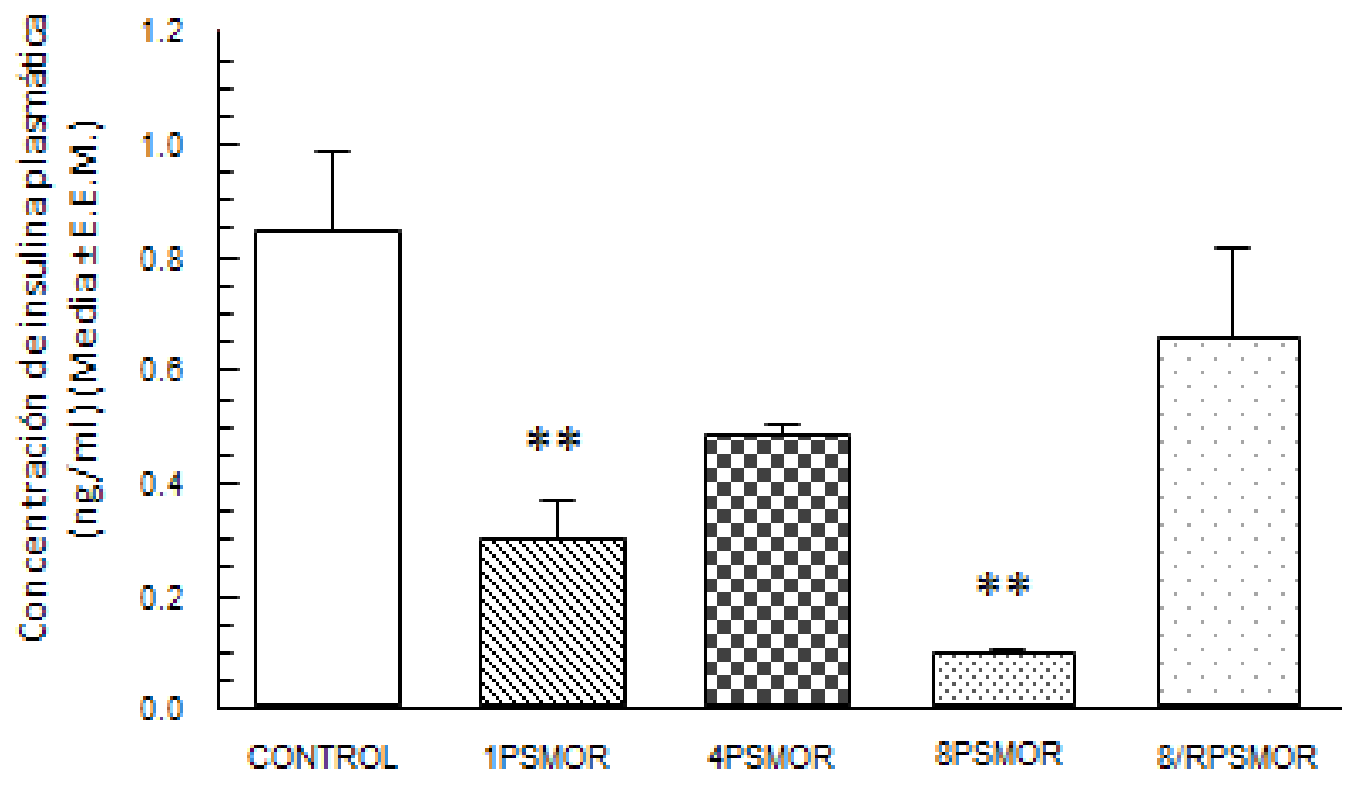

Fig.3 Efecto de diferentes periodos de PSMOR sobre los niveles plasmáticos de insulina, se observa una disminución en la concentración de insulina desde el día 1 de PSMOR, misma que se restablecerse posterior al periodo de recuperación. $(n=5)$ Media $\pm E E M$, ANOVA seguida de Newman Keuls, Diferencia significativa con respecto al grupo control ${ }^{* *} p<0.01$ ${ }^{*} p<0.05$. 


\subsection{Efecto de la PSMOR sobre el panel de lípidos}

Debido a las alteraciones que ya habían sido observadas evaluamos el efecto de los diferentes periodos de PSMOR y 20 días de recuperación sobre las concentraciones de triglicéridos, HDL, LDL, VLDL y colesterol. Se observó una considerable alteración metabólica en los lípidos desde el día 1 de PSMOR con una tendencia a recuperar los niveles después de la suspensión de la misma, con 20 días de recuperación. Las concentraciones de triglicéridos disminuyen significativamente desde el día 1 de PSMOR $(p<0.001)$, en el caso de las HDL su concentración disminuye significativamente al día 4 de PSMOR $(p<0.05)$, condición que continúa siendo marcada al día 8 de PSMOR.

En el caso de las VLDL, todos los tiempos de PSMOR tienen efecto, induciendo una disminución significativa desde el día 1 de PSMOR $(P<0.001)$ y hasta el día 8 de PSMOR $(p<0.001)$.

En todos los parámetros lipídicos analizados se observan niveles dentro del rango normal después de 20 días de recuperación, esto considerado así al no presentar diferencias estadísticas en relación al grupo control. Los niveles de colesterol no se modificaron en ningún momento por la PSMOR. 


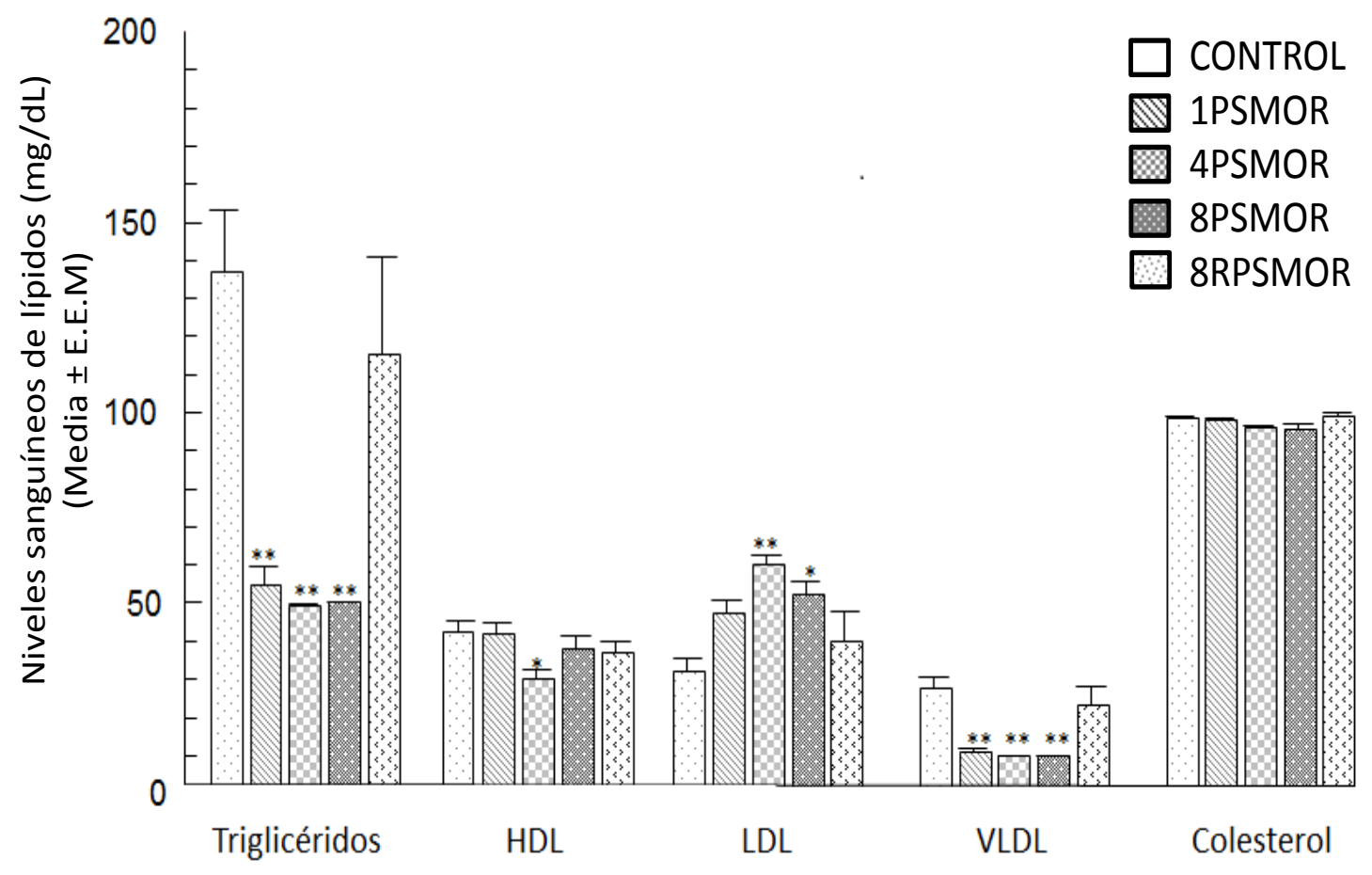

Figura 4. Niveles séricos de triglicéridos, HDL LDL, VLDL y colesterol. La PSMOR induce descensos en los niveles de triglicéridos, HDL y VLDL, mientras que los niveles de LDL se incrementan. $(n=5)$ Media $\pm E E M$, ANOVA seguida de Tukey, diferencia significativa con respecto al grupo control ${ }^{* *} \mathrm{p}<0.01{ }^{*} \mathrm{p}<0.05$. 


\subsection{Efecto de la PSMOR sobre los niveles plasmáticos de corticosterona}

Al evaluar el efecto de la PSMOR sobre los niveles de corticosterona encontramos que esta hormona presenta un incremento estadísticamente significativo sólo en los animales con 8 días de PSMOR $(p<0.01)$, incrementándose 9 veces su valor (2447.7ng/mL) a los 8 días de PSMOR en relación al grupo control $(234.28 \mathrm{ng} / \mathrm{mL})$, efecto que se mantiene aún después de los 20 días de recuperación, este valor es significativamente menor con respecto al día 8 de PSMOR $(p<0.01)$.

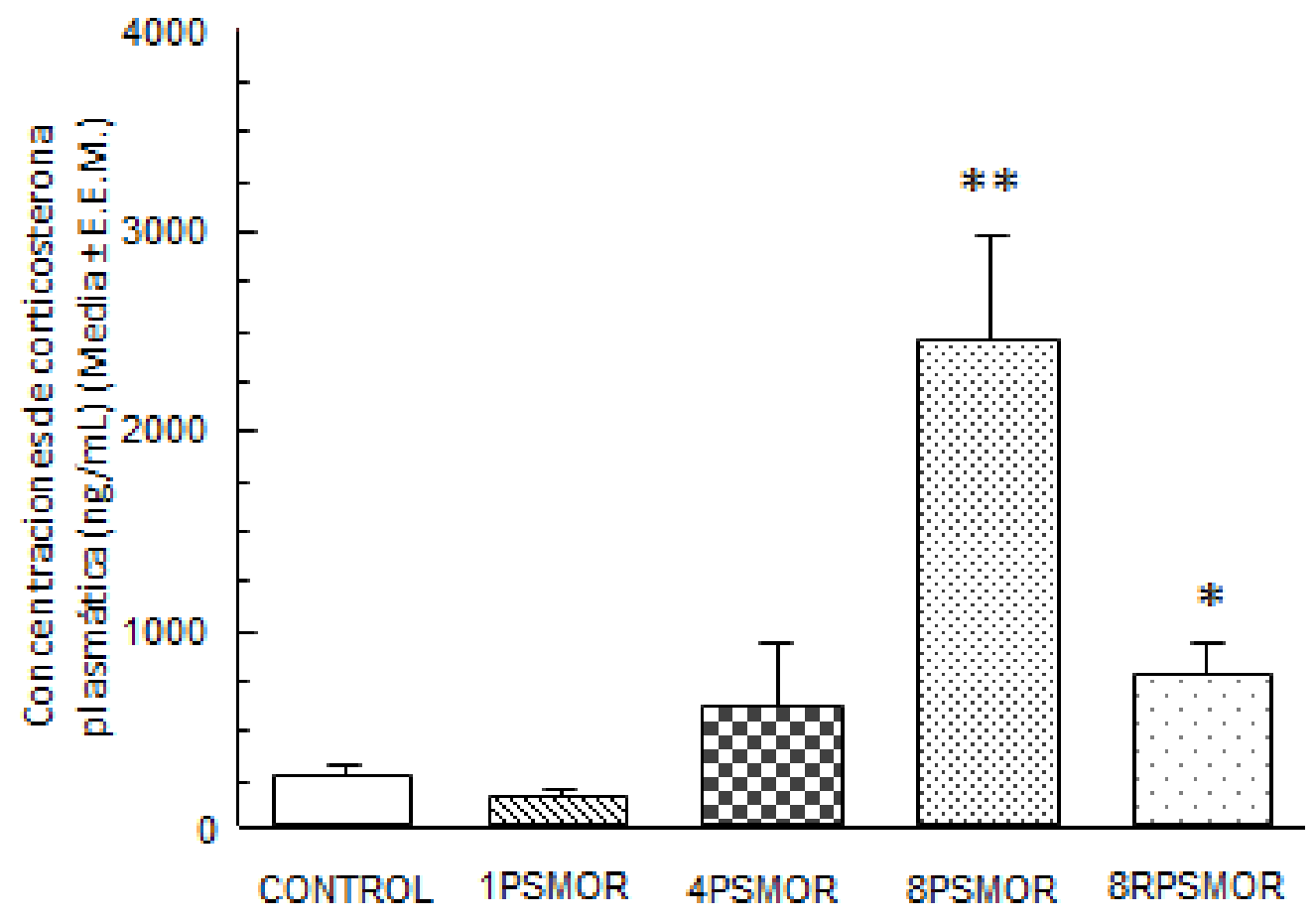

Fig. 5 Efecto de diferentes periodos de PSMOR sobre las concentraciones de corticosterona. La PSMOR induce un incremento significativo sólo al día 8 de PSMOR, condición que se mantiene después de 20 días de recuperación. $(n=5)$ Media $\pm E E M$, ANOVA, seguida de Newman Keuls, diferencias significativas con respecto al grupo control ${ }^{* *} \mathrm{p}<0.01^{*} \mathrm{p}<0.05$. 


\subsection{Efecto de la PSMOR sobre los niveles séricos de grelina y leptina}

En la evaluación de las hormonas reguladoras del apetito encontramos que las concentraciones de grelina presentan una tendencia a incrementarse desde el día 1 de PSMOR (Fig. 6A), sin embargo conforme avanzan los días de PSMOR se eleva de manera significativa $(p<0.05)$. La concentración de grelina al día 8 de PSMOR, incrementó 7 veces su valor $(0.983 \mathrm{ng} / \mathrm{mL})$ en relación al grupo control $(0.1177$ $\mathrm{ng} / \mathrm{mL}$ ) condición que parece restablecerse posterior a los 20 días de recuperación (Figura 6A). Respecto a las concentraciones de leptina (Fig. 6B), observamos que esta hormona disminuye significativa y progresivamente conforme avanza el tiempo de PSMOR, al día 1 de PSMOR ( $p<0.0001)$ las concentraciones son $41.5 \%$ menores $(17.18 \mathrm{ng} / \mathrm{mL})$ con respecto al grupo control $(29.41 \mathrm{ng} / \mathrm{mL})$, conforme avanza el periodo de PSMOR los niveles séricos a los 8 días de PSMOR $(1.81 \mathrm{ng} / \mathrm{mL})$, son $93.8 \%$ menores con respecto al grupo control $(p<0.005)$. Posterior a los 20 días de recuperación, los animales se restablecen en cuanto a las concentraciones circulantes de leptina y grelina. 
$(A)$

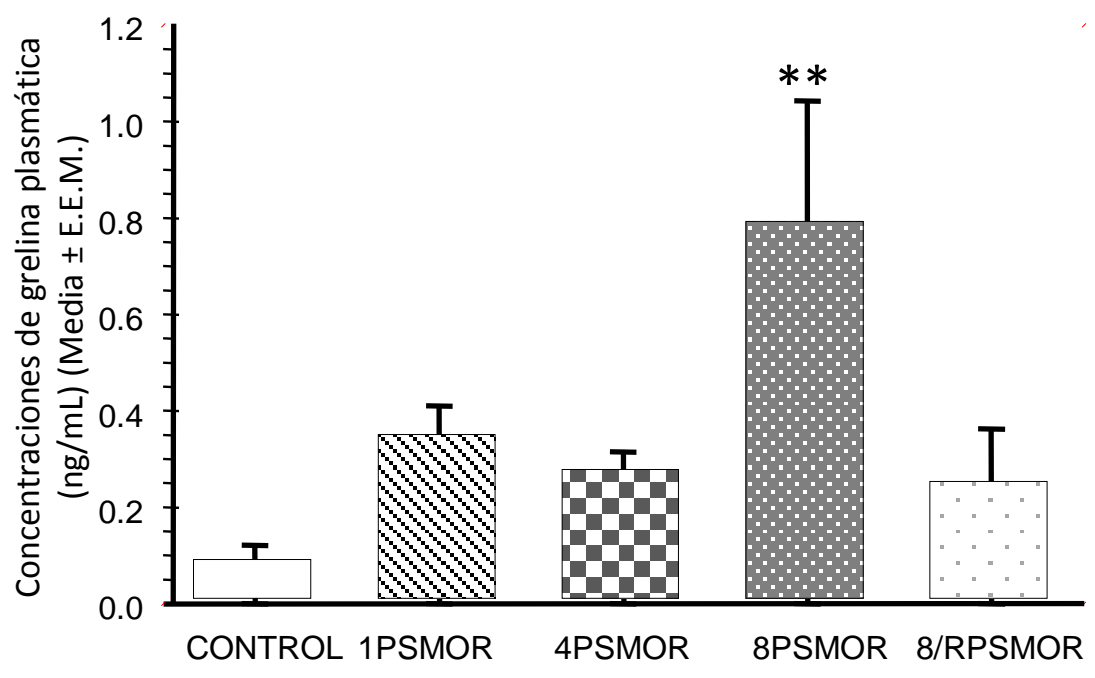

(B)

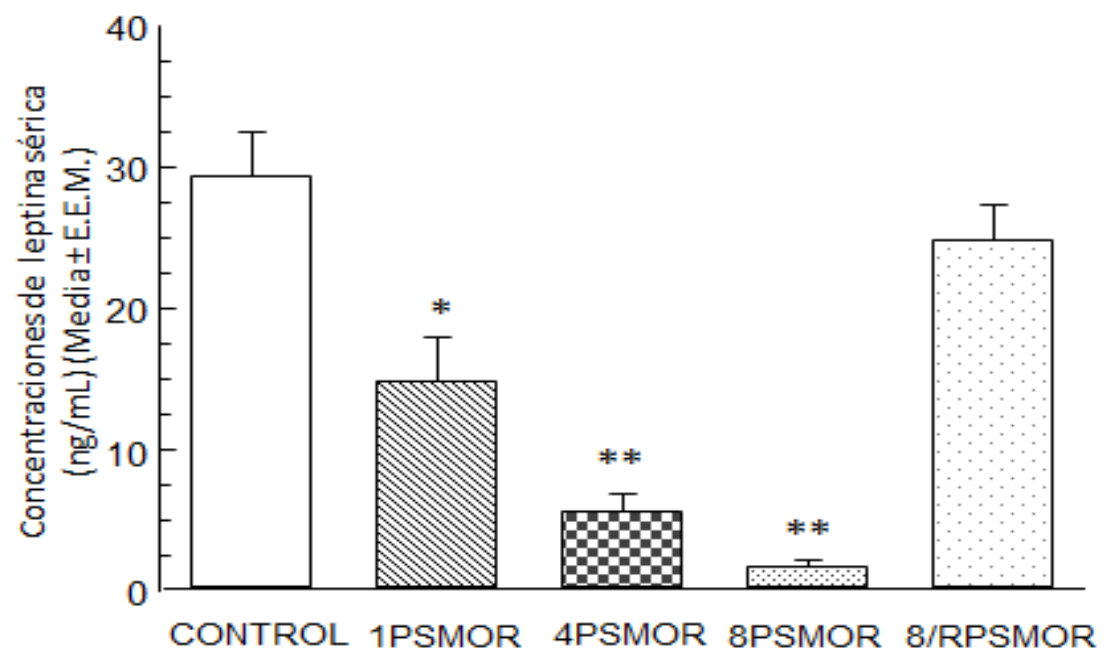

Figura 6. Efecto de la PSMOR sobre las concentraciones de grelina (A) y leptina (B). la PSMOR induce un aumento en los niveles de grelina, estadísticamente significativo al día 8 de PSMOR y una disminución progresiva en los niveles séricos de leptina $(n=5)$ Media $\pm E E M$, ANOVA seguida de Newman Keuls, diferencias significativas con respecto al grupo control ${ }^{* *} p<0.01{ }^{*} p<0.05$. 


\subsection{Efecto de la PSMOR sobre los niveles séricos de IL-6}

Finalmente observamos que las concentraciones plasmáticas de IL-6 se incrementan por efecto de la PSMOR (Fig. 7). Presentando un aumento significativo después de 1 y 8 días de PSMOR $(p<0.0001)$, aunque tiende a disminuirse en el día 4 de PSMOR, sin embargo este no alcanza a ser significativo. Después de 20 días de recuperación, los niveles de IL-6 no se restablecen, observándose un incremento estadísticamente significativo en este grupo $(p<0.001)$. Precisamente en donde la concentración de IL6 se encuentra incrementada 1.5 veces $(0.79 \mathrm{ng} / \mathrm{mL})$ en relación al grupo control $(0.34 \mathrm{ng} / \mathrm{mL})$.

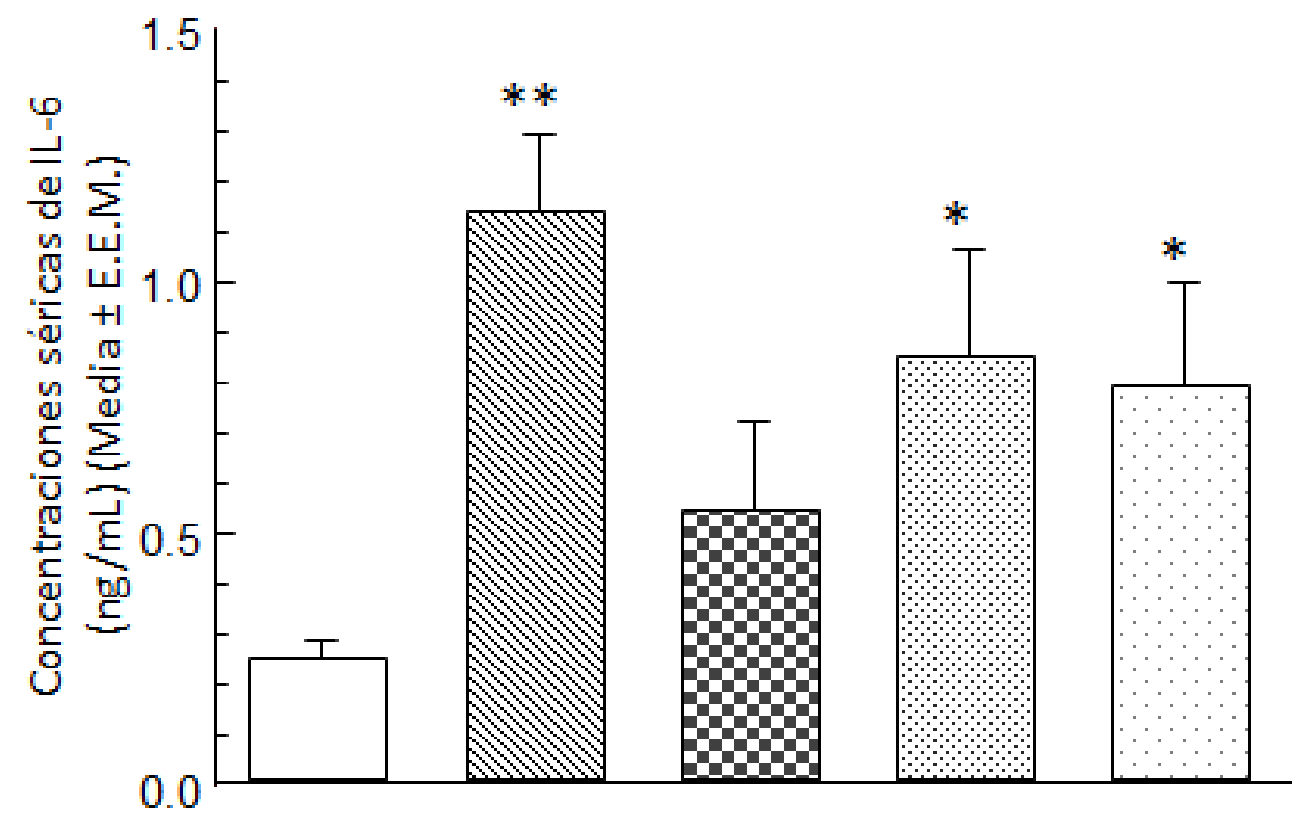

CONTROL1PSMOR 4PSMOR 8PSMOR 8RPSMOR

Fig. 7 Efecto de diferentes periodos de PSMOR sobre IL-6. La PSMOR, induce un aumento en las concentraciones plasmáticas de IL-6 el día 1 y 8 de PSMOR, así como después de 20 días de recuperación. $(n=5)$ Media土EEM, ANOVA, seguida de comparaciones múltiples por Newman Keuls, diferencias significativas en relación al grupo control ${ }^{* *} p<0.01{ }^{*} p<0.05$. 


\subsection{Integración de resultados}

Los resultados que obtuvimos indican una disminución progresiva del peso corporal la cuales proporcional al tiempo de PSMOR, dicho efecto no es reversible posterior a 20 días de recuperación. La PSMOR induce hipoglucemia basal en los diferentes periodos evaluados de PSMOR, durante la PTGO la hipoglucemia se mantiene constante en cada grupo, pero curiosamente se observó un incremento en las concentraciones de glucosa a los 30 min en el grupo de recuperación.

Para el caso de la insulina se observó una disminución en la concentración de la misma desde el día 1 de PSMOR, misma que se restablece posterior al periodo de recuperación. La PSMOR induce bajos niveles de triglicéridos, HDL y VLDL e incrementos en la concentración de LDL. La PSMOR induce un aumento significativo en los niveles de corticosterona sólo después de 4 días de PSMOR, condición que se mantiene a pesar de transcurridos 20 días de recuperación.

La PSMOR por 8 días también induce un incremento en los niveles de grelina y una disminución progresiva en los niveles de leptina. Finalmente las concentraciones plasmáticas de IL-6 se incrementan de manera significativa por efecto de la PSMOR después de 1 y 8 días de PSMOR, mientras que después de 20 días de recuperación estos niveles no se restablecen. 


\begin{tabular}{|c|c|c|c|c|}
\hline Parámetro & 1 PSMOR & 4 PSMOR & 8 PSMOR & 8 PSMOR/R \\
\hline Peso corporal & - & $\downarrow$ & $\downarrow$ & $\downarrow$ \\
\hline Glucosa & $\downarrow$ & $\downarrow$ & $\downarrow$ & $\uparrow$ \\
\hline Insulina & $\downarrow$ & - & $\downarrow$ & - \\
\hline Triglicéridos & $\downarrow$ & $\downarrow$ & $\downarrow$ & - \\
\hline HDL & - & $\downarrow$ & - & - \\
\hline LDL & - & $\uparrow$ & $\uparrow$ & - \\
\hline VLDL & $\downarrow$ & $\downarrow$ & $\downarrow$ & - \\
\hline Corticosterona & - & - & $\uparrow$ & $\uparrow$ \\
\hline Grelina & - & - & $\uparrow$ & - \\
\hline Leptina & $\downarrow$ & $\downarrow$ & $\downarrow$ & - \\
\hline IL-6 & $\uparrow$ & - & $\uparrow$ & $\uparrow$ \\
\hline
\end{tabular}

Tabla 1. Tabla comparativa sobre las modificaciones derivadas de los diferentes periodos de PSMOR y su recuperación. 


\section{DISCUSIÓN}

En el presente estudio observamos importantes alteraciones en el metabolismo tanto de glucosa como lípidos dependientes del tiempo de PSMOR, así como una correlación negativa en las concentraciones de las hormonas reguladoras del apetito (leptina y grelina) que de igual manera son dependientes al tiempo de PSMOR. Observamos un incremento importante en los niveles de corticosterona hasta por encima de 9 veces de su valor inicial, sin embargo esto sucedió hasta el día 8 de PSMOR, donde tanto los triglicéridos como las concentraciones de glucosa son muy bajas en relación al grupo control y en el caso de la insulina también se observa una disminución en su concentración que se enfatiza conforme avanza el periodo de PSMOR. Para el caso de la citocina proinflamatoria IL-6 se muestra una respuesta aguda de incremento desde el día 1 de PSMOR, algunos de los parámetros analizados como el perfil de lípidos y las concentraciones circulantes de hormonas reguladoras del metabolismo se restablecen a sus niveles iniciales posterior a 20 días de recuperación después de haber sido sometidas a 8 días de PSMOR, sin embargo algunos otros parámetros como las concentraciones de glucosa, los niveles circulantes de IL-6, las concentraciones de costicosterona así como el peso corporal, son alteraciones derivadas de la PSMOR que no se restablecen pasando 20 días de recuperación.

Cuando la PTS y en particular la PSMOR, se experimenta en ratas por algunos días o por varias semanas, los efectos que se desarrollan pueden conducir a un aumento de la morbilidad, lo que se refiere en conjunto como "efectos de la privación de sueño" (Rechtschaffen y Bergmann, 2002), los cuales fueron descritos por primera vez por los mismos autores (Rechtschaffen y Gillialand, 1983). Utilizando el método del disco sobre agua (DOW) por sus siglas en inglés, los efectos que se observaron incluyen hiperfagia, pérdida de peso corporal, elevado gasto energético, incremento en la concentración de catecolaminas plasmáticas, hipotiroidismo, disminución de la temperatura corporal, importante deterioro de la apariencia física, así como reducción en niveles de hormonas anabólicas. (Everson y Crowley, 2004) y disminución de la 
integridad del sistema inmune (Everson y Toth, 2000). La etiología de la mayoría de estas alteraciones aun permanece en la oscuridad, a pesar de que se han realizado importantes avances (Everson y Crowley, 2004; Everson y Nowak, 2002; Everson y Toth, 2000). La adaptabilidad a la pérdida de sueño es imposible pues siempre resulta fatal cuando la privación de sueño se realiza de manera total (Everson y Bergmann, 1989) o selectiva de SMOR (Kushida y Bergmann, 1989). La privación selectiva de SMOR se ha realizado de manera sencilla y eficaz con el método de plataforma única, también conocido como el método del florero invertido, este consiste en colocar al animal de experimentación que por lo regular es una rata en una pequeña plataforma (el ejemplo es de un florero invertido rodeado de agua, el fundamento del método se basa en la pérdida del tono muscular que se origina específicamente durante el SMOR, lo que permite que el animal toque o caiga al agua y despierte bruscamente, repitiéndose este evento una y otra vez. La electroencefalografía de las ratas en la plataforma confirma que la mayoría del tiempo de SMOR y cantidades variables de sueño NMOR se pierden (Grahnstedt, 1985; Hilakivi, 1984; Mendelson, 1974; Machado, 2004), lo que ha corroborado y validado su utilidad.

Existen importantes evidencias que demuestran que la PTS y en particular la PSMOR conducen a una reducción en la masa corporal, un incremento en el metabolismo energético, cambios en hormonas circulantes, pérdida de integridad inmunológica, entre otros trastornos (Everson y Bergmann, 1989; Koban y Swinson, 2005). Es importante destacar que, muchos de los efectos reconocidos como graves inducidos por la PS se manifiestan después de una semana (Rechtschaffen y Bergmann, 2002), no se ha logrado determinar y evaluar el momento de aparición y progresión de tales efectos, aunado a que casi todos los estudios realizados han sido a corto plazo, normalmente con una duración no mayor a 96 horas (Andersen, 2004; Brock, 1994; Coll- Andreu, 1989; Papakonstantinou, 2003; Patchev, 1991). 
A pesar de las diferencias entre los métodos de privación, existen efectos persistentes independientes al método elegido, como la hiperfagia acompañada de la pérdida de peso corporal (Brock, 1994; Papakonstantinou, 2003; Rechtschaffen y Bergmann, 2002). Estos efectos han sido observados en diferentes paradigmas de privación crónica de sueño, por ejemplo con el método DOW desarrollado por Rechtschaffen y Bergmann (Everson, 1989; Kushida 1989). Así mismo se han evaluado los patrones de consumo de alimento y peso corporal en la PSMOR por el método de florero invertido (Cohen, 1965; Elomma, 1979; Koban y Sita, 2008). Este método ha sido el más utilizado, sin embargo no todos los resultados obtenidos muestran consistencia. Se ha observado que si la duración de PS es de 4 a 6 días, algunos de los estudios reportan hiperfagia (Elomma, 1979; Bhanot, 1989; Brock, 1994, Suchecki y Tufik, 2000; Suchecki, 2003). Mientras que algunos otros estudios no observan dicho comportamiento (Mendelson, 1974; Balestrieri, 1989; Youngblood, 1999; Elomma 1981). Es importante resaltar que si el periodo de PS se extiende por 10 o más días, siempre se induce hiperfagia acompañada de pérdida de peso corporal (Koban, 2005; Koban, 2006).

En el presente trabajo observamos que la pérdida de peso es progresiva pero comienza a ser significativa a partir del día 4 de PSMOR, continuando así hasta el día 8, precisamente hasta el día en que finaliza la PSMOR, lo que sugiere que la PSMOR es un factor crítico para inducir el establecimiento de estos efectos. Además, las ratas que privamos crónicamente de SMOR no recuperan su peso luego de 17 días de reposo. Hasta el momento no se puede suponer que no se recuperan en algún momento, nuestros datos sugieren que esta recuperación podría implicar un periodo de tiempo muy largo para poder restablecer incluso el peso original de los animales. Con base a ello se ha llegado muchas veces a la controversia de conocer porque los roedores presentan una marcada disminución del peso corporal en relación a lo que ocurre con los humanos, esto puede ser explicado de varias formas. 
Una de ellas podría ser que el método de PSMOR en roedores induce una PS mucho más extensa y por periodos crónicos, pero también resulta importante el hecho de que existe una diferencia entre la tasa metabólica de los roedores en comparación a la que presentamos los humanos, sin embargo se ha estipulado que el sorprendente gasto energético al que los animales se encuentran expuestos no puede ser exclusivamente atribuible a la vigilia perpetua (Bergmann, 1989). Es importante mencionar que existen reportes que señalan que el incremento en el consumo de alimento precede a la importante pérdida de peso en animales privados tanto de sueño total como de SMOR (Everson, 1989). Por eso mismo se ha sugerido que la PS aumenta la motivación para el consumo de alimento. Sin embargo, un estudio sugiere que los animales con PSMOR por el método de plataformas múltiples muestra una disminución en la motivación de los animales para obtener alimento como recompensa (Erin, 2005). Al mismo tiempo se ha comprobado que la disminución del peso corporal observada durante la PS prolongada puede encontrarse menos marcada cuando las ratas son alimentadas con una dieta elevada en calorías (Everson, 1993) lo que nos lleva a sugerir la presencia de importantes alteraciones metabólicas en los animales privados de sueño.

Se ha observado, también que la PSMOR por un periodo de 96 horas induce un incremento en la ingesta de sacarosa, pero a pesar de ello, no se ve incrementado el consumo de agua (Suchecki, 2003), se ha reportado también que ratas privadas de SMOR prefieren en su dieta una ingesta mas abundante de carbohidratos, esto es similar a lo que se observa en estudios realizados en humanos con PS (Spiegel, 2004). Algunos otros estudios han demostrado que las ratas con PSMOR por el método de plataformas múltiples muestran un incremento en la actividad locomotora en el plazo que dura la PSMOR, comparado con su grupo control (Martínez, 2004). Esta puede ser otra posible causa que favorece la pérdida de peso corporal.

Existen evidencias de que hay una regulación hacia concentraciones altas del neuropéptido $\mathrm{Y}$ orexigénico (NPY) en el núcleo arcuato hipotalámico, así como una regulación a la baja de la hormona estimulante del melanocito tipo alfa ( $\alpha-\mathrm{MSH})$ la $-57-$ 
cual tiene una función anorexigénica (Koban \& Le, 2006) y el comportamiento hiperfágico durante la PS se ha atribuido al incremento de la expresión hipotalámica de NPY, situación que se acompaña de la reducción de los niveles circulantes de leptina como respuesta a la pérdida de sueño (Spiegel, 2004).

Por desgracia ningún estudio ha podido comprobar la relación que existe entre el NPY y la concentración de orexina en la hiperfagia que se induce por la PSMOR, pero se ha visto que la recuperación de sueño reduce la expresión de NPY que rápidamente lleva a los animales a una condición de hipofagia (Martins, 2010) al mismo tiempo se sabe que la PS incrementa el gasto energético conduciendo a un desequilibrio energético negativo y a una reducción de glucógeno hepático, asi como una disminución de los niveles de triglicéridos en suero a pesar de la hiperfagia (Martins, 2010).

Se cree que la función que desempeña la orexina en el proceso de PS es la de mantener el equilibrio tanto de NPY como de leptina e insulina. Por lo anterior, algunos de los mecanismos que media el aumento en el consumo de alimento, sin ganacia de peso corporal se ha ido conociendo poco a poco, la respuesta hiperfágica se ha vinculado con una disminución en la concentración de leptina circulante y un incremento en las concentraciones de grelina (Everson, 2004; Koban, 2005) efectos que nosotros hemos corroborado en este trabajo.

La disminución plasmática de leptina es un efecto persistente e indudablemente inducido por la PS (Everson, 2004; Koban, 2006; Hanlon,2002). Nosotros observamos una disminución de los niveles de leptina inversamente proporcional a la duración de PSMOR, en otras palabras, una progresiva reducción de los niveles circulantes de leptina desde el día 1 de PSMOR en el cual se observa el mayor efecto. Se ha reportado que la PSMOR produce una rápida disminución de los niveles de leptina en suero que se mantienen bajos luego de 20 días de PSMOR (Koban, 2005). Este mismo efecto se ha asociado con una drástica reducción de tejido adiposo (Rosa Neto, 2010). Este fenómeno hasta cierto punto resulta lógico si 
se toma en cuenta que la leptina es liberada por los adipocitos como respuesta a los cambios en el balance energético (Havel, 2004), sin embargo si consideramos que la PS es un estresor por si mismo, debemos también considerar la diversidad de funciones neuroendócrinas en las que la leptina esta involucrándose, uno de los efectos que produce el estrés es alterar el patrón de la ingesta de alimento aumentándolo (Maniam, 2012).

El sistema encargado de la regulación de la respuesta de estrés: el eje hipotálamohipófisis-adrenales (HHA) o también conocido como eje del estrés, entre múltiples funciones también tiene la de regular la respuesta de ingesta de alimento pues sus respectivos circuitos neuronales convergen en el núcleo paraventricular, el cual contiene neuronas que tienen hormona liberadora de corticotropina $(\mathrm{CRH})$, lo que quiere decir que los sistemas que controlan la ingesta de alimento y la respuesta de estrés comparten el mismo sitio cerebral, lo que puede favorecer a que cada sistema influya en el otro para generar una respuesta.

Se sabe que el estrés altera la ingesta de alimento de manera bidireccional, lo que quiere decir que puede inducir a una disminución o incremento en la ingesta de alimento, sin embargo estos efectos responden a mecanismos complejos $y$ miltifactoriales, en donde se incluyen los niveles de glucocorticoides (dependiente del periodo e intensidad del estresor). La interacción entre los glucocorticoides y la alimentación se relaciona con neuropéptidos como el NPY, la MSH-a, la proteína relacionada con Agouti (AgRP), melanocortinas y sus receptores, $\mathrm{CRH}$, urocortina y señales periféricas (leptina, insulina y grelina) (Maniam, 2012).

En este sentido, los efectos de la PSMOR sobre los niveles de leptina pueden estar formando parte de la respuesta al estrés. La leptina que ha sido producida y secretada por el tejido adiposo, lleva la señal a varios centros cerebrales sobre el almacenamiento de grasa en diferentes regiones del cuerpo, esto a través de sus receptores expresados tanto a nivel central como periférico, de este modo puede ejecutar una gran cantidad de funciones reguladoras relacionadas con la ingesta de 
alimento y el metabolismo, entre ellas se encuentra la de regular la actividad del eje HHA (Zhang, 2005).

Diversos estudios han demostrado la capacidad de la leptina para reducir la actividad del eje HHA en respuesta al estrés a través de acciones que se ejercen sobre diversos componentes y a diferentes niveles del HHA, Esta interacción se lleva a cabo a nivel del hipotálamo (especialmente en el núcleo paraventricular), la glándula hipófisis (por acción de los corticotropos) y la glándula adrenal, en la liberación de corticosteroides necesarios para una adecuada adaptación a condiciones de estrés (Jessop,1999). Así, se ha reportado, por ejemplo que la leptina inhibe la síntesis y liberación de glucocorticoides adrenales (Bornstein, 1997; Kruse, 1998) y también reduce la magnitud y duración de la secreción de la ACTH inducida por estrés (Trottier, 1998; Oates, 2000). Además, se ha demostrado que la leptina puede prevenir las respuestas del HHA inducida por la administración de leptina en ratas (Giovambattista, 2000) y atenuar la elevación de ACTH y cortisol después de estrés impredecible en mono Rhesus (Wilson, 2005), así como de ACTH y corticosterona inducido por estrés por inmovilización (Heiman, 1997) y por ejercicio en ratas (Huang, 2006).

En sentido opuesto, los glucocorticoides son capaces de estimular la síntesis y secreción de leptina (DeVos, 1995; Slieker, 1996). La leptina circulante podría limitar la actividad del HHA mediante la inhibición de la liberación de $\mathrm{CRH}$.

Durante el estrés agudo y crónico, así como en la PSMOR, la disminución en la secresión de leptina puede facilitar la capacidad de respuesta del HHA, que parece ser importante para la superviviencia. Siendo así que la disminución progresiva de los niveles circulantes de leptina inducida por la PSMOR observada en nuestros resultados podrían manifestar una progresiva disminución en la eficiencia para regular el HHA por mecanismos de retroalimentación negativa, un progresivo cambio en la respuesta metabólica cuando la PSMOR se vuelve crónica y una eminente 
desregulación de la respuesta al estrés inducida por la PSMOR, como ha sido sugerido por algunos autores (Spiegel, 2004).

Esto refuerza la idea de que existe una estrecha relación entre la homeostasis energética y el control del sueño, se ha demostrado que las orexinas juegan un papel importante en el mantenimiento de la vigilia, lo que se demuestra con la deficiencia de señalización de la orexina en el trastorno de sueño conocido como narcolepsia (Chemelli, 1999).

Por otro lado, la perdida del peso corporal o la incapacidad de ganancia de peso de los animales durante la PSMOR también puede ser explicada por la aparición de un mayor gasto energético y una tasa metabólica en reposo, mediada por el incremento en la expresión de la proteína desacoplante de la cadena respiratoria tipo 1 (UCP-1) en las mitocondrias del tejido adiposo pardo (Koban, 2005). La UCP-1 se expresa solamente en la mitocondria del tejido adiposo pardo y desacopla las oxidoreducciones de la fosforilación de ADP, liberando energía en forma de calor. Esto ocurre de manera particular cuando la grasa parda es estimulada por el frío, vía las fibras simpáticas que la inervan y en menor grado, después de una excesiva ingesta de alimentos (Zaninivich, 2005). Estos cambios concuerdan con el mejor entendimiento de los mecanismos fisiológicos que estimulan el consumo de alimento (Schwarts, 2000).

Este trabajo nos permite observar que la PSMOR induce un incremento casi progresivo de los niveles en suero de grelina en oposición a la progresiva disminución de leptina. La secreción de grelina se incrementa bajo condiciones negativas de balance energético como el hambre, caquexia y anorexia nerviosa, mientras que sus concentraciones disminuyen en condición de balance energético positivo, tales como son la alimentación, hiperglucemia y obesidad. Además de tener un poderoso efecto sobre la secreción de $\mathrm{GH}$, la grelina estimula la ingesta de alimentos, regula la homeostasis de la glucosa y transduce señales a los núcleos hipotalámicos reguladores que controlan la homeostasis energética (Hosoda, 2006). 
La grelina es una hormona peptídica producida por el tracto gastrointestinal (Kojima, 1999). Evidencias recientes indican que la grelina también participa en la respuesta fisiológica a varias formas de estrés (Patterson, 2010). Se ha observado que los niveles de grelina plasmática se incrementan en respuesta al estrés inducido por la restricción calórica aguda y crónica (Tschop, 2001; Ariyasu, 2001; Perello, 2010; Perello, 2011). La grelina también se incrementa en respuesta a varias formas de estrés psicológico, por ejemplo, se han observado elevaciones en la expresión del gen para grelina gástrica y de grelina en suero de roedores como respuesta al estrés agudo, incluido el estrés por pinchamiento de cola y por falta de agua (Asakawa, 2001; Kristenssson, 2006). Los incrementos en los niveles plasmáticos de grelina también se presentan por el estrés inducido por la defensa social o por la inmersión continua en una caja con agua (Lutter, 2008; Ochi, 2008; Chuang, 2011). Es importante hacer mencion de que los humanos sometidos a estrés psicosocial agudo también muestran un incremento en las concentraciones de grelina en sangre (Rouach, 2007), sin embargo, el circuito por el cual la grelina participa en la regulación de estas respuestas aun no es claro.

De igual manera que la leptina, un mecanismo potencial podría incluir la activación del eje neuroendócrino HHA, el cual podría ser blanco de las acciones de la grelina. En respuesta al estrés por PSMOR, la activación de las neuronas productoras de $\mathrm{CRH}$ del núcleo paraventricular hipotalámico da lugar a la secreción de $\mathrm{CRH}$ en la eminencia media y a una subsecuente estimulación de la secreción de ACTH por la hipófisis (Smith, 2006). A su vez la ACTH actúa sobre la corteza adrenal para inducir la liberación de glucocorticoides, los cuales tienen una variedad de importantes efectos que incluyen el incremento de la glicemia y de peso corporal (Dallman, 2006), más recientemente se ha documentado que la grelina tiene un papel activador del HHA (Wren, 2002; Mozid, 2003) y al parecer a nivel hipotalámico. Por ejemplo: la grelina induce la liberación de $\mathrm{CRH}$ de tejido hipotalámico in vitro (Wren, 2002; Mozid, 2003). También la administración central de grelina estimula la 
expresión del RNAm para $\mathrm{CRH}$ en el hipotálamo e incrementa los niveles plasmáticos de ACTH y glucocorticoides en roedores (Stevanovic, 2007).

Es importante destacar que la administración de grelina estimula fuertemente la liberación de ACTH y cortisol en humanos delgados y saludables (Takaya, 2000; Locatelli, 2010). Existe una reciente evidencia que sugiere que la grelina previene la ansiedad excesiva en condiciones de estrés crónico (Spencer, 2012; Currie, 2012). Sin embargo aún no esta claro, si los efectos de la grelina sobre el HHA se producen a través de la regulación directa de neuronas productoras de $\mathrm{CRH}$ o por vías indirectas. La grelina podría activar al HHA con el efecto de inducir la liberación de $\mathrm{CRH}$. Durante el paso de la privación aguda a crónica de SMOR, el aumento en la secreción de grelina podría facilitar la capacidad de respuesta del HHA, que parece ser importante para la superviviencia, sobre todo ante estresores que impliquen un elevado desgaste energético que sobrepasa las reservas energéticas. Estudios con ratones knockout para grelina, muestran que después de 4 días de una severa restricción calórica del $60 \%$ del consumo normal de alimento a $40 \%$ y al punto de perder cerca del $30 \%$ de peso corporal y $75 \%$ de grasa corporal, los ratones mostraron una caída en las concentraciones de glucosa en sangre en un rango de 12 - $36 \mathrm{mg} / \mathrm{dL}$ en comparación con los niveles de 58-76 mg/dL del grupo control. Luego de 7-8 días los ratones knockout presentaban una apariencia física de desgaste y grave decaimiento, momento en el cual empezaron a morir, mientras que el grupo control en restricción calórica mostró un progresivo aumento en los niveles de grelina plasmática, los ratones knockout no tenían grelina detectable, por otra parte la infusión de hormona de crecimiento o de grelina normalizaron los niveles de glucosa en sangre en ratones knockout y evitaron su muerte (Zhao, 2010).

Es importante destacar que, a pesar de la deficiencia de grelina, los ratones knockout estaban hambrientos, como lo indica la ingesta de todo su alimento en tan solo 1 hora, lo que quiere decir que la grelina no es escencial para la presencia de la conducta del hambre durante los periodos de inanición (Zhao, 2010). Estos resultados sugieren que la función de la grelina es elevar los niveles de la GR 
durante periodos de severa restricción calórica y desequilibrio energético negativo, como el que se presenta en la privación crónica de SMOR, no para incrementar la ingesta de alimento sino para asegurar niveles suficientes de glucosa en sangre con el fin de permitir la sobrevivencia y prevenir la muerte (Zhao, 2010).

Así que, el aumento de la grelina en suero inducida por 8 días de PSMOR puede estar denotando el intento del organismo para regular el HHA y los niveles de glucosa sanguínea, en condiciones de resistencia metabólica y periodos de severa restricción calórica que empiezan a volverse crónicos y cuyos efectos pueden incluso amenazar la sobrevivencia misma.

Puntualizando en lo que ocurre con el metabolismo de la glucosa durante la PSMOR, nuestros resultados correspondientes a la PTGO reflejan una marcada hipoglucemia a partir del día 4 de PSMOR, los niveles de glucosa basales disminuyeron desde el día 1 de PSMOR, mientras que al día 8 de la PSMOR, la hipoglucemia es muy severa y se refleja antes y después de la carga de dextrosa anhidra por vía intragástrica, dicha respuesta implica una evidente alteración en el metabolismo de la glucosa, estas alteraciones se relacionan con el alto desgaste metabólico al que han sido sometidos los animales por la PSMOR.

Es bien sabido que los niveles sanguíneos de glucosa se encuentran altamente regulados pues la TG es la capacidad de metabolizar la glucosa exógena y volver al estado basal, esto se evalúa clínicamente a partir de la PTGO, esta tolerancia depende fundamentalmente de la capacidad que tienen las células $\beta$ pancreáticas para la liberación de insulina y se convierte en resistencia a la insulina cuando se necesitan mayores cantidades de insulina para reducir los niveles de glucosa en el torrente sanguíneo (Van Cauter, 1997). La PTGO es en la actualidad la prueba más utilizada para el diagnóstico de la resistencia a la insulina (una de las patologías que componen al llamado SM y que permite el desarrollo de la DT2). En el desarrollo de la prueba, la administración de dextrosa permite evaluar el efecto biológico de la insulina, en el índice basal se evalúa la sensibilidad hepática a la insulina, mientras 
que la evaluación de las concentraciones de glucosa e insulina luego de la carga, dan una evaluación más certera de la sensibilidad insulínica corporal total, hepática y periférica (Mitrakou, 1990).

La intolerancia a la glucosa se caracteriza por una respuesta anormal a una sobrecarga de glucosa o dextrosa administrada vía oral, este estado se asocia a una mayor prevalencia de patología cardiovascular y al riesgo de desarrollar DT2. En la etiopatología de la DT2 se sabe que el primer evento en la secuencia que conduce al desarrollo de la enfermedad, es la RI, lo que lleva a un incremento de la síntesis y secreción de insulina así como un hiperinsulinismo compensatorio capaz de mantener la homeostasis metabólica por algunos años, una vez que se rompe este nuevo equilibrio entre la $\mathrm{RI}$ y la secreción de la misma se da inicio a la IG y posteriormente el desarrollo de la DT2 (Atkinson, 1994).

Se sabe que durante el sueño, en la primera mitad de la noche, el metabolismo de la glucosa es mas lento, predominantemente durante la fase de SOL, lo que es asociado a una disminución en la asimilación de glucosa cerebral (Nofzinger, 2002), estos efectos se ven invertidos durante la segunda mitad de la noche, especialmente en la fase de SMOR, por tanto, la pérdida de sueño puede tener efectos negativos sobre el metabolismo de la glucosa convirtiéndose en un importante factor que favorece el desarrollo de la RI.

Existen reportes en donde se menciona que las principales modificaciones metabólicas que acompañan a la PS son el aumento en la RI y la disminución de la TG (Van Helder , 2003), por lo anterior podemos decir que en nuestros animales experimentales con PSMOR se da una respuesta satisfactoria a la insulina liberada pero es de considerarse que existe una alteración metabólica de la glucosa, se sabe que durante la fase de SMOR existe una reducción de la tasa metabólica corporal en relación a la que se presenta en el estado de vigilia, lo que lleva a proponer que los animales con PSMOR al no tener esta fase crucial de sueño se someten a una prueba de resistencia metabólica muy alarmante. Sin embargo el metabolismo 
energético no solo se centra en la regulación de la glucosa, de ahí la necesidad de conocer la relación entre el metabolismo energético de lípidos y la PS.

Se han realizado algunos estudios de regresión logística que relacionan la duración de PS y los niveles de colesterol, triglicéridos, HDL y LDL, y se han reportado asociaciones de tipo $U$ entre la PS y los niveles de lípidos con las cuales se ha sugerido que la restricción de sueño puede ser considerado un factor de riesgo que desencadene enfermedades cardiovasculares, ya que un incremento en el nivel de triglicéridos o una disminución de HDL son importantes factores de riesgo para este tipo de enfermedades (Jappensen, 1997).

En los resultados que obtuvimos podemos observar que al día 4 de PSMOR se presentan los niveles más bajos de HDL, efecto que el organismo trata de revertir con forme se incrementa el periodo de PSMOR. Como se ha comentado previamente, se sabe que durante la restricción de sueño disminuyen las concentraciones de leptina, favoreciendo el apetito de los individuos (Guilleminault, 2003, Taheri, 2004), sin embargo se ha observado que de manera curiosa al administrar leptina de manera exógena, disminuyen los niveles séricos de triglicéridos (Oral, 2002). Por tanto se ha propuesto que los mecanismos dados por la disminución en la concentración en sangre de leptina y el incremento en la concentración de grelina por la restricción de sueño, pueden estar involucradas en la asociación entre la corta duración de sueño y la dislipidemia, sin embargo, los mecanismos que subyacen a estas asociaciones siguen sin estar claros, es importante destacar que solo pocos estudios han investigado la asociación de parámetros de sueño y el nivel de lípidos, y que parte de los resultados obtenidos resultan contradictorios.

En un estudio se encontró una disminución de las LDL en humanos privados de sueño, pero este estudio utilizó medidas de autoinforme para determinar la duración del sueño (Bjorvath, 2007). En nuestro estudio encontramos una importante alteración a la alta en las concentraciones de LDL siendo más evidente al día 4 de 
PSMOR, condición que persiste a mayor exposición de PSMOR. Algunos estudios han informado que un sueño fragmentado se relaciona con una concentración mayor de colesterol total y un perfil de lípidos menos favorable (Ekstedt, 2004).

incremento del riesgo de enfermedades cardiovasculares en pacientes con apnea obstructiva crónica del sueño (SAOS) por sus siglas en inglés, se ha tratado de explicar principalmente por la exposición de la hipoxia intermitente que puede conducir a un estrés oxidante, proceso inflamatorio, aterosclerosis, disfunción endotelial e HA (Foster, 2007). Otros estudios sostienen que es la obesidad y no el SAOS el principal determinante de las anormalidades en los lípidos así como otras alteraciones metabólicas (Sharma, 2007), Existen estudios que revelan asociaciones entre la disminución de HDL en condiciones de restricción de sueño, así como un mayor periodo de sueño en mujeres con DT2 (Williams, 2007). Algunos autores han estudiado a adultos jóvenes mediante polisomnografía y han encontrado que el tiempo de sueño tiene una relación positiva con la relación LDL/HDL (Ekstedt, 2004). Por otro lado, la VLDL es una molécula cuyo tamaño es directamente proporcional a su contenido de triglicéridos e inversamente proporcional al contenido de proteínas y fosfolípidos, así mismo la LDL es uno de los principales vehículos para el transporte de colesterol en el torrente sanguíneo, mientras que la HDL contiene cantidades aproximadamente iguales de los lípidos y proteínas (Skipski, 1972).

En procesos fisiopatológicos, los niveles elevados de triglicéridos y de lipoproteínas ricas en triglicéridos, se reconocen como posibles factores en la conducción de procesos ateroscleróticos, sobretodo en lesiones leves a moderadas. La triada que se da por niveles elevados de triglicéridos, bajos niveles de HDL y un predominio de LDL como partículas pequeñas, recibe el nombre de dislipidemia aterogénica (NCEP, 2002). Algunos estudios sugieren que la reducción de triglicéridos de manera rápida puede ayudar a convertir LDL en partículas menos aterogénicas (Marz, 2004). Vinculado a otros procesos metabólicos, la Rl es una característica común de hipertrigliceridemia y a esta condición le puede favorecer reducir el aclaramiento de los triglicéridos circulantes, el aumento del flujo periférico de ácidos grasos libres y la 
lipogénesis bajo la influencia de la insulina, así como la promoción de la secreción de lipoproteínas ricas en triglicéridos como es la LDL por el hígado (Reaven, 2005). Así mismo la hipertrigliceridemia, en conjunto con la resistencia a la insulina, se han relacionado con el aumento en la circulación de marcadores de inflamación sistémica como TNF- $\alpha$, IL-6 y P-CR (Jonkers, 2002). Las HDL son una clase mixta de lipoproteínas que comprenden las diferentes subespecies con diferentes apolipoproteínas y varían en la composición de los lípidos, las densidades y probablemente tienen propiedades diferentes en cuanto a revertir el transporte de colesterol o de antioxidantes. (Nobecourt, 2005). Se ha postulado que el trastorno inicial en la Rl se genera en el adipocito por una incapacidad en el almacenamiento de ácidos grasos, generando el aumento de flujo hacia el hígado con el subsiguiente aumento en la formación de VLDL (Ginsberg, 2000). El intercambio de triglicéridos y ésteres de colesterol entre las VLDL con las HDL y las LDL pueden enriquecer de triglicéridos a las HDL, y su hidrólisis genera partículas de LDL pequeñas y densas, junto con una menor cantidad de HDL (Blades, 1993), estas condiciones están siendo alteradas de manera inmediata al efecto de PSMOR, vemos que al descender las concentraciones de triglicéridos lo hacen también las HDL, condición relacionada con las concetraciones nuevas de triglicéridos en circulación, sin embargo la movilidad de los mismos puede estar siendo acompañada y relacionable con el incremento en las concentraciones de LDL.

Se ha establecido que una concentración plasmática baja de HDL constituye un factor de riesgo coronario independiente, al igual que las VLDL remanentes ricas en colesterol y potencialmente aterogénicas (Gordon, 1989). El hígado desempeña un papel crucial en el mantenimiento de la homeostasis lipídica, siendo importante su función en la síntesis de determinadas apoproteínas, de las VLDL y de las LDL, así como la intervención en el aclaramiento de lipoproteínas remanentes y de las LDL, es importante también su función reguladora de depósitos de colesterol en el organismo por su capacidad de formación y eliminación de ácidos biliares. (Havel, 1985). Las elevadas cifras de colesterol y triglicéridos, corresponden al incremento 
en las concentraciones de VLDL y particularmente de LDL, ambas lipoproteínas muestran un contenido muy elevado de triglicéridos y se puede sospechar que su aumento en el plasma tenga un doble origen: por un lado por el aumento de la secreción desde el hígado de VLDL enriquecidas de triglicéridos (Felker, 1982) y por otro lado como consecuencia de esta composición es posible un catabolismo disminuido en ambas clases de lipoproteínas, insistiendo que en el caso de las VLDL también se encuentran modificaciones en su composición proteica. Al contrario de las otras lipoproteínas, las HDL se encuentran disminuidas en algunas patologías hepáticas, lo que indica que estos individuos presentan menor número de partículas de HDL, lo que parece deberse a una disminución en la síntesis hepática (Fujii, 1981).

Las HDL son partículas de origen no bien establecido, estrechamente relacionadas con el transporte reverso del colesterol, lo que se refiere al fujo del colesterol desde la célula de la pared vascular hacia el hígado, una enzima importante en este procesos es la LPL (lipoproteín-lipasa) que es responsable de la hidrólisis de los triglicéridos en el plasma y se encuentra en altas concentraciones en el tejido adiposo en donde su actividad es inducida por la insulina al igual que en el músculo estriado. Existen diferencias importantes en el perfil lipídico de las personas que padecen hipertrigliceridemia, perfil plasmático que puede verse aun mas modificado cuando la hipertrigliceridemia se asocia con el incremento de la RI. El reemplazo de los ésteres de colesterol de las HDL por triglicéridos reduce la cantidad de colesterol transportado por las HDL en el camino reverso del colesterol, esto explica porque la hipertrigliceridemia y la baja concentración de HDL son factores de riesgo para la aterosclerosis, de esta forma también se explica porqué las personas con hipertrigliceridemia tienen bajas concentraciones de HDL. Un mecanismo similar explica la presencia de LDL pequeñas y densas en pacientes por hipertrigliceridemia, el intercambio de ésteres de colesterol de las LDL por triglicéridos hace que estas LDL "ricas en triglicéridos" sean un buen sustrato para las HDL, que extrayendo los triglicéridos de las LDL las transforma en partículas mas pequeñas y densas, 
formando las LDL reconocidas por su poder aterogénico y por su correlación con la hipertrigliceridemia, en particular aquella que se presenta en el SM o la DT2. Se sabe que las partículas de LDL ricas en triglicéridos tienen alteraciones estructurales en las apoB-100 que hacen que la interacción con el receptor LDL se vea alterada y la remoción (mediada por receptor apo B) se dificulta.

Se ha propuesto que la interacción entre el sueño y la obesidad podría relacionarse a través de un balance en el patrón neuroendócrino regulador del apetito y el balance energético (Knutson, 2007). En un estudio realizado a 11 hombres adultos sanos expuestos a una PS de 4 horas por noche por 6 noches, se observó que la concentración sérica de leptina disminuyó significativamente (Spiegel, 1999), un estudio posterior confirmó estos hallazgos además de mostrar un incremento de un $18 \%$ de grelina (Spiegel, 2004). Algunos autores han afirmado que es suficiente con solo 1 día de PS para que las concentraciones circulantes de grelina se vean incrementadas (Schmid, 2008). La restricción de sueño entonces, podría estar asociada con una modificación de pétidos hipotalámicos reguladores del apetitosaciedad, en especial el sistema de neuropétido orexina (Prinz, 2004), este sistema se expresa en el hipotálamo lateral y posterior, región relacionada con el control del apetito y que evoca la conducta de alimentación en los animales (Adamantidis, 2009) e inerva regiones cerebrales involucradas en la regulación del ciclo sueño- vigilia y del SNA (Willie, 2001).

Algunos estudios de PS sugieren que una alteración de los mecanismos neuroendócrinos relacionados con el balance del apetito-saciedad, pueden subyacer los efectos del acortamiento del tiempo de sueño en ganancia de peso, debido a que la restricción aguda no es sostenible en el tiempo, es poco evidente de que forma esos cambios podrían corresponderse con una condición crónica de restricción de sueño, como se espera a nivel social y poblacional. Resulta casi imposible separar cada una de las vertientes que se tienen como objeto de estudio de este proyecto, el sistema regulatorio aún no se encuentra identificado y puede ser que varios sistemas u órganos estén colaborando para el desarrollo de una misma función de respuesta 
ante la PSMOR, por ejemplo las misma modificaciones en las concentraciones de leptina pueden estar afectando los componentes reguladores del metabolismo de la glucosa, del apetito e incluso estar modificando la producción de adipocinas (Ranjabaran, 2009), específicamente de IL-6 para este caso, la elevación crónica de citocinas puede contribuir a problemas de salud que incluyan daño cardiovascular, alteraciones endócrinas, alteraciones en el estado deánimo y trastornos de sueño (Frey, 2007). Un dato importante se da a partir de la observación en personas con PS que muestran un incremento en la unión del factor de transcripción NF-kB (vía de señalización de IL-6) al DNA, la activación del mismo se cree que contribuye a la fisiopatología de enfermedades como la DT2, enfermedad cardiovascular y aterosclerosis (Bierhaus, 2003).

\section{CONCLUSIONES}

Existen importantes alteraciones metabólicas derivadas de la PSMOR, mismas que son dependientes al tiempo de exposición. Las alteraciones derivadas de la PSMOR sobre los niveles de hormonas reguladoras del apetito (leptina y grelina) se manifiestan sólo en el tiempo en que los animales han sido expuestos a esta condición, son suficientes 20 días para que los niveles circulantes de las hormonas regresen a su estado de normalidad, por tanto la PSMOR no tiene un efecto que altere directamente el punto regulador de las hormonas. Las alteraciones que se observan en los niveles de lípidos en general, son dependientes de tiempo de PSMOR, estas alteraciones son únicamente relacionables con el gasto energético que se presenta por la PSMOR y no por la regulación en el balance de los mismos. Modificaciones en las concentraciones de corticosterona, glucosa e IL-6 muestran que la PSMOR esta íntimamente relacionada con un proceso de estrés fisiológico, este proceso no logra restablecerse después de 20 días de eliminar la PSMOR, por lo que sus centros reguladores pueden ser alterados por la misma PSMOR. Un periodo de reposo de 20 días posterior a 8 días de PSMOR, no son suficientes para 
restablecer a los animales a su fisiología normal, por lo anterior concluimos que el efecto de la PSMOR sobre el metabolismo energético induce importantes alteraciones que se mantienen por un periodo muy prolongado de tiempo. A partir de estos estudios nuevas interrogantes y nuevas líneas de investigación se deberán abrir en el futuro, entre las porpuestas que planteamos para la continuidad de nuestro proyecto, es sumamente necesario determinar el consumo de alimento por animal para poder realizar una relación de resultados mas completa, debido a las observaciones en el presente trabajo consideramos importante analizar la expresión de moléculas relacionadas con la expresión génica en la regulación del metabolismo como los PPAR's, UCP-1, FAPT y ACLS, tambien evaluando para el caso de PPAR los índices de expresión tanto del receptor como de su regulador (RXR), consideramos necesario complementar los resultados con la evaluación de niveles circulantes de adiponectina al ser una citocina anti-inflamatoria.

\section{REFERENCIAS}

1. Adamantidis A, De Lecea L. (2009).The hypocretins as sensors for metabolism and arousal. J Physiol ; 587: 33-40.

2. Adult Treatment Panel III. (2002). Third Report of the National CholesteroL Education Program (NCEP) Expert Panel on Detection, Evaluation, and Treatment of High Blood Cholesterol in Adults (Adult Treatment Panel III) final report. Circulation; 106:3143-3421.

3. Aljada A, Mohanty P, Ghanim H, Abdo T, Tripathy D, Chaudhuri A, Dandona P. (2002). Increase in intranuclear nuclear factor kappaB and decrease in inhibitor kappaB in mononuclear cells after a mixed meal: evidence for a proinflammatory effect. Am J Clin Nutr ; 79:682-90.

4. Andersen M, Bignotto M, Machado R, Tufik S. (2004). Different stress modalities result in distinct steroid hormone responses by male rats. Braz J Med Biol Res; 37: 791-797.

5. Ariyasu H, Takaya K, Tagami T, Ogawa Y, Hosoda K. (2001). Stomach is a major source of circulating ghrelin, and feeding state determines plasma ghrelin-like immunoreactivity levels in humans. J Clin Endocrinol Metab; 86:4753-4758.

6. Asala S, Okano Y, Honda K, Inoue E. (1990). Effects of medial preoptic area lesions on sleep and wakefulness in unrestrained rats. Neurosci Lett; 114(3): 300-304.

7. Asakawa A, Inui A, Kaga T, Yuzuriha H, Nagata T. (2001). A role of ghrelin in neuroendocrine and behavioral responses to stress in mice. Neuroendocrinol; 74:143147. 
8. Atkinson M, Maclaren NK. (1994). The pathogenesis of insulin dependent Diabetes Mellitus New. Engl. J.Med; 331: 1428-36.

9. Ayas N, White D, AL-Delaimy W, Manson J, Stampfer M, Speizer F, Patel S, Hu FB. (2003). A prospective study of self-reported sleep duration and incident diabetes in women. Diabetes Care; 26(2):380-384.

10. Aydin S, Aydin S, Ozkan Y, Kumru S. (2006). Ghrelin is present in human colostrum, transitional and mature milk. Peptides; 27: 878-82.

11. Balestrieri S, D'Onofrio G, Giuditta A. (1980). Deprivation of paradoxical sleep. Effect on weight and nucleic acid content of liver and brain. Neurochem Res ;5:1251-64.

12. Barone M, Menna-Barreto L. (2011).Diabetes and sleep: a complex cause-and-effect relationship. Diabetes Res Clin Pract; 91(2):129-37.

13. Benington J, Heller H. (1995). Restoration of brain energy metabolism as the function of sleep. Prog Neurobiol ;45:347-360.

14. Bergmann B, Everson C, Kushida C, Fang V, Leitch. (1989). Sleep deprivation in the rat: V. Energy use and mediation. Sleep; 12:31-41.

15. Bhanot J, Chhina G, Singh B, Sachdeva U, Kumar V. (1989). REM sleep deprivation and food intake. Indian J Physiol Pharmacol; 33:139-45.

16. Bierhaus A, Wolf J, Andrassy M, Rohleder N, Humpert P, Petrov D, Ferstl R, von Eynatten M, Wendt T, Rudofsky G, Joswig M, Morcos M, Schwaninger M, McEwen B, Kirschbaum C, Nawroth P. (2003). A mechanism converting psychosocial stress into mononuclear cell activation. Proc Natl Acad Sci USA; 100:1920-5.

17. Bjorvatn B, Sagen I, Øyane N, Waage S, Fetveit A, Pallesen S, Ursin R. (2007). The association between sleep duration, body mass index and metabolic measures in the Hordaland Health Study. J Sleep Res ;16:66-76.

18. Blades B, Vega G, Grundy S. (1993) Activities of lipoprotein lipase and hepatic triglyceride lipase in postheparin plasma of patients with low concentrations of HDL cholesterol. Arterioscler Thromb; 13: 1227-1235.

19. Bonnet M, Arand D. (2001). Clinical effects of sleep fragmentation versus sleep deprivation. Sleep Med ;3(7):297-310.

20. Borbely A. (1982). A two process model of sleepregulation. Hum. Neurobiol; 1, 195 204.

21. Borbély A, Tobler I. (1985). Homeostatic and circadian principles in sleep regulation in the rat. En: McGinty D, Drucker-Colín R, Morrison A, Parmeggiani P (Eds) Brain mechanisms of sleep; Raven Press, New York. Pp 35-44.

22. Bornstein S, UhImann K, Haidan A, Ehrhart-Bornstein M, Scherbaum WA. (1997). Evidence for a novel peripheral action of leptin as a metabolic signal to the adrenal gland: leptin inhibits cortisol release directly. Diabetes ;46 1235-1238.

23. Brock J, Farooqui S, Ross K, Payne S, Prasad C. (1994). Stress-related behavior and central norepinephrine concentrations in the REM sleep-deprived rat. Physiol Behav; 55:997-1003.

24. Chase M, Morales F. (1994). The control of motoneurons during sleep. En: Kryger MH, Roth T, Dement WC (Eds) Principles and practice of sleep medicine. Saunders WB, Philadelphia; Pp 163-175.

25. Chemelli R, Willie J, Sinton C, Elmquist J, Scammell T, Lee C, Richardson J, Williams S, Xiong Y, Kisanuki Y, Fitch TE, Nakazato M, Hammer RE, Saper C, Yanagisawa M. (1999). Narcolepsy in orexin knockout mice: molecular genetics of sleep regulation. Cell; 98:437-451.

26. Chuang J, Perello M, Sakata I, Osborne-Lawrence S, Savitt J. (2011). Ghrelin mediates stress-induced food-reward behavior in mice. J Clin Invest; 121:2684-2692. 
27. Coenen A, Van Luijtelaar E.(1985). Stress induced by three procedures of deprivation of paradoxical sleep. Physiol Behav;35 (4):501-4.

28. Cohen H, Dement W.(1965). Sleep: changes in threshold to electroconvulsive shock in rats after deprivation of "paradoxical" phase. Science; 3;150(701):1318-9.

29. Coll A, Ayora M, Trullas O, Morgado B. (1989). Behavioral evaluation of the stress induced by the platform method for short-term paradoxical sleep deprivation in rats. Brain Res Bull; 22: 825-828.

30. Considine R, Sinha M, Heiman M, Kriauciunas A, Stephens T, Nyce M. (1996). Serum immunoreactive-leptin concentrations in normal-weight and obese humans. $N$ Engl J Med; 334:292-5.

31. Currie P, Khelemsky R, Rigsbee E, Dono L, Coiro C, Chapman C, Hinchcliff K. (2012). Ghrelin is an orexigenic peptide and elicits anxiety-like behaviors following administration into discrete regions of the hypothalamus.Behav Brain Res;1;226(1):96105.

32. Dallman M, Pecoraro N, La Fleur S, Warne J, Ginsberg A. (2006). Glucocorticoids, chronic stress, and obesity. Prog Brain Res; 153:75-105.

33. Dandona P, Aljada A, Chaudhuri A. (2005). Metabolic syndrome: a comprehensive perspective based on interactions between obesity, diabetes, and inflammation. Circulation ; 111:1448-54.

34. DeVos P, Saladin R, Auwerx J, Staels B. (1995). Induction of ob gene expression by corticosteroids is accompanied by body weight loss and reduced food intake. J Biol Chem; 270:15958-15961.

35. Dzaja A, Dalal M, Himmerich H, Uhr M, Pollmacher T, Schuld A.(2004). Sleep enhances nocturnal plasma ghrelin levels in healthy subjects. Am J Physiol Endocrinol Metab; 286:E963-7.

36. Ekstedt M, Åkerstedt T, So"derstro"m M. (2004). Microarousals during sleep are associated with increased levels of lipids, cortisol, and blood pressure. Psychosom Med; 66:925-31.

37. Elomaa E. (1979). The cuff pedestal: an alternative to flowerpots? Physiol Behav; 23:669-72.

38. Elomaa E. (1981). The light/dark difference in meal size in the laboratory rat on a standard diet is abolished during REM sleep deprivation. Physiol Behav; 26:487-93.

39. Escobedo D, Escamilla C, Santos B. (1994). Colesterol sérico y diabetes mellitus: Principales factores de riesgo independientes en la mortalidad por cardiopatía isquémica en México. Arch Inst Cardiol Mex; 64: 189-195.

40. Ettaro L, Songer T, Zhang P, Engelgau M. (2004). Cost-of-illness studies in diabetes mellitus. Pharmacoeconomics; 22:149-64.

41. Erin C, Matthew E, Bridgette K, Ann E, Ruth M. (2005). The effect of REM sleep deprivation on motivation for food reward, Behav Brain Res;30;163 (1):58-69.

42. Eversen, C. (1997). Sleep deprivation and the immune system. In: Pressman, M.R.,Orr, W.C. Eds, Understanding Sleep. American Psychological Association, Washington; pp. 401-424.

43. Everson C, Bergmann B, Rechtschaffen A. (1989). Sleep deprivation in the rat: III. Total sleep deprivation. Sleep; 12:13-21.

44. Everson C and Toth L. (2000). Systemic bacterial invasion induced by sleep deprivation. Am J Physiol Regul Integr Comp Physiol; 278: R905-R916.

45. Everson C, Nowak T Jr. (2002). Hypothalamic thyrotropin-releasing hormone mRNA responses to hypothyroxinemia induced by sleep deprivation. Am J Physiol Endocrinol Metab; 283: E85-E93. 
46. Everson, Everson C, Crowley W. (2004). Reductions in circulating anabolic hormones induced by sustained sleep deprivation in rats. Am J Physiol Endocrinol Metab; 286:E1060-70.

47. Everson C, Wehr T.(1993). Nutritional and metabolic adaptations to prolonged sleep deprivation in the rat. Am J Physiol; 264:376-87.

48. Felker T. Hamilton R. Vigne J. Havel R. (1982). Properties of lipoproteins in blood plasma and liver perfusates of rats with cholestasis . Gastroenterol; 83:652-663.

49. Foster G, Poulin M, Hanly P. (2007). Sleep apnoea \& hypertension: physiological bases for a causal relation: intermittent hypoxia and vascular function: implications for obstructive sleep apnoea. Exp Physiol; 92:51- 65.

50. Franken P, Tobler I, Borbély A. (1991). Slepp homeostasis in the rat: simulation of the time couse of EEG slow-wave activity. Neurosci Lett;16;130(2):141-4.

51. Frey D, Fleshner M, Wright K Jr.(2007). The effects of 40 hours of total sleep deprivation on inflammatory markers in healthy young adults. Brain Behav Immun; 21:1050-7.

52. Fujii S, Koga S, Shono T, Yamamoto K, Ibayashi H.(1981). Serum apoprotein A-I and A-II in liver desease and cholestasis. Clim Chim Acta; 115: 321 - 331.

53. Gallup Organization, editors. (1995). Gallup organization; Sleep in America.

54. Germain A, Nielsen T. (2003). Sleep pathophysiology in PTSD and idiopathic nightmare sufferers. Biol Psychiatr, 54:1092-8.

55. Ginsberg H. (2000). Insulin resistance and cardiovascular disease. J Clin Invest; 106: 453-458.

56. Giovambattista A, Chisari A, Gaillard R, Spinedi E. (2000) Food intake-induced leptin secretion modulates hypothalamo-pituitary-adrenal axis response and hypothalamic Ob$\mathrm{Rb}$ expression to insulin administration. Neuroendocrinol; 72 341-349.

57. Gordon D, Probstfield J, Garrison R, Neaton J, Castelli W, Knoke J. (1989). Highdensity lipoprotein cholesterol and cardiovascular disease. Four prospective American studies. Circulation; 79: 8-15.

58. Gottesmann C. (1997). Introduction to the neurophysiological study of sleep: central regulation of skeletal and ocular activies. Arch Ital Biol; 135(3): 279-314.

59. Graaf C, Blom W, Smeets P, Stafleu A, Hendriks H. (2004). Biomarkers of satiation and satiety. Am J Clin Nutr; 79: 946-61.

60. Grahnstedt S, Ursin R. (1985). Platform sleep deprivation affects deep slow wave sleep in addition to REM sleep. Behav Brain Res; 18: 233-239.

61. Gruetter R.(2003). Glycogen: the forgotten cerebral energy store. J Neurosci Res; 74:179-183.

62. Guilleminault C, Powell N, Martinez S. (2003). Preliminary observations on the effects of sleep time in a sleep restriction paradigm. Sleep Med; 4:177-84.

63. Guerre-Millo M. (2004). Adipose tissue and adipokines: for better or worse. Diabetes Metab; 30:13-19.

64. Haack M, Kraus T, Schuld A, Dalal M, Koethe D, Pollmächer T .(2002). Diurnal variations of interleukin- 6 plasma levels are confounded by blood drawing procedures. Psychoneuroendocrinol; 27:921-31.

65. Hanlon E, Harder B, Obermeyer W, Kelley A, and Benca R. (2002). The effect of sleep deprivation on plasma leptin levels in rats (Abstract). Soc Neurosc; Program No. 897.

66. Hauner H.(2005). Secretory factors from human adipose tissue and their functional role. Proc Nutr Soc; 64:163-169.

67. Havel R. (1985). Role of the liver in atherosclerosis. Arteriosclerosis; 5:569- 580. 
68. Havel R. (2004). Update on adipocyte hormones: regulation of energy balance and carbohydrate/lipid metabolism. Diabetes; 53, Suppl 1: S143-S151.

69. Heiman M, Ahima R, Craft L, Schoner B, Stephens T, Flier J. (1997). Leptin inhibition of the hypothalamic-pituitary-adrenal axis in response to stress. Endocrinol; 138 38593863.

70. Hicks R, Moore J, Haynes C, Phillips N, Hawkins J. (1979). REM sleep deprivation increases aggressiveness in male rats. Physiol Behav; 22:1097-100.

71. Hilakivi I, Peder M, Elomaa E, Johansson G. (1984). Validation of the cuff pedestal technique for rapid eye movement sleep (REMs) deprivation by electrophysiological recordings. Physiol Behav; 32: 945-947.

72. Horne J. (2002). Why sleep? Biologist; 49:213-216.

73. Hosoda H, Kojima M, Kangawa K. (2006). Biological, physiological, and pharmacological aspects of ghrelin. J Pharmacol Sci; 100(5):398-410.

74. Huang Q, Timofeeva E, Richard D. (2006). Regulation of corticotropin-releasing factor and its types 1 and 2 receptors by leptin in rats subjected to treadmill running-induced stress. J Endocrinol; 191(1):179-88.

75. Imaki M, Hatanaka Y, Ogawa Y, Yoshida Y, Tanada S. (2002). An epidemiological study on relationship between the hours of sleep and life style factors in Japanese factory workers. J Physiol Anthropol Appl Human Sci ; 21:115-20.

76. Irwin M, Wang M, Ribeiro D, Cho H, Olmstead R, Breen E, Martinez-Maza O, Cole S. (2008). Sleep loss activates cellular inflammatory signaling. Biol Psychiatry; 64:538-40.

77. Jean-Louis G, Kripke D, Ancoli S. (2000). Sleep and quality of well-being. Sleep; 23:1115-1121.

78. Jennings J, Muldoon M, Hall M. (2007). Self-reported sleep quality is associated with the metabolic syndrome. Sleep; 30: 219-223.

79. Jeppesen J, Hein H, Suadicani P, Gyntelberg F. (1997). Relation of high TG-low HDL cholesterol and LDL cholesterol to the incidence of ischemic heart disease. An 8-year follow-up in the Copenhagen Male Study. Arterioscler Thromb Vasc Biol; 17:1114-20.

80. Jessop D. (1999). Central non-glucocorticoid inhibitors of the hypothalamo-pituitaryadrenal axis. J Endocrinol; 160(2):169-80.

81. Jones B. (1998). The neural basis of consciousness across the sleep-waking cycle. In: Jasper, H.H., Descarries, L., Castellucci, V.F., Rossignol, S. (Eds.), Consciousness: At the Frontiers of Neuroscience, Advances in Neurology, vol. 77, Lippincott- Raven, Philadelphia; pp. 75-94.

82. Jonkers I, Mohrschladt M, Westendorp R.(2002). Severe hypertriglyceridemia with insulin resistance is associated with systemic inflammation: reversal with bezafibrate therapy in a randomized controlled trial. Am J Med; 112:275-280.

83. Jouvet D, Vimont P, Delorme F, Jouvet M (1964). Study of selective deprivation of the paradoxal sleep phase in the cat. (in French). C. R. Seances Soc. Biol. Fil; 158: 756-759.

84. Kipke D, Garfinkel L, Wingard D, Klauber M, Marler M. (2002). Mortality associated with sleep duration and insomnia. Arch. Gen. Psychiatry; 59:131-136.

85. Knutson K. (2007). Impact of sleep and sleep loss on glucose homeostasis and appetite regulation. Sleep Med Clin; 2: 187-97.

86. Knutson K, Spiegel K, Penev P, Van Cauter E. (2008). The metabolic consequences of sleep deprivation. Sleep Med Rev; 11: 163-178.

87. Koban M, Le W, Hoffman G. (2006). Changes in hypothalamic corticotropin-releasing hormone, neuropeptide $\mathrm{Y}$, and proopiomelanocortin gene expression during chronic rapid eye movement sleep deprivation of rats. Endocrinology; 147:421-31. 
88. Koban M, Sita L, Le W, Hoffman G.(2008). Sleep deprivation of rats: the hyperphagic response is real. Sleep; 31:927-33.

89. Koban M, Stewart C. (2006). Effects of age on recovery of body weight following REM sleep deprivation of rats. Physiol Behav; 87:1-6.

90. Koban M, Swinson K. (2005).Chronic REM-sleep deprivation of rats elevates metabolic rate and increases UCP1 gene expression in brown adipose tissue. Am J Physiol Endocrinol Metab Physiol; 289:E68-74.

91. Kojima M, Hosoda H, Date Y, Nakazato M, Matsuo H. (1999). Ghrelin is a growthhormone-releasing acylated peptide from stomach. Nature; 402:656-660.

92. Kristenssson E, Sundqvist M, Astin M, Kjerling M, Mattsson H. (2006). Acute psychological stress raises plasma ghrelin in the rat. Regul Pept; 134:114-117.

93. Kristiansen O, Mandrup-Poulsen T. (2005). Interleukin-6 and diabetes. Diabetes; 54 : S114-124.

94. Kripke D, Simons R, Garfinkel L, Hammond E. (1979). Short and long sleep and sleeping pills. Is increased mortality associated? Arch Gen Psychiatry; 36: 103-116.

95. Krueger J, Rector D, Churchhill L. (2007). Sleep and cytokines. Sleep Med Clin; 2(2):161-9.

96. Kruse M, Bornstein S, UhImann K, Paeth G, Scherbaum W. (1998). Leptin downregulates the steroid producing system in the adrenal. Endocrine Research;24 587-590.

97. Kushida C, Bergmann B, Rechtschaffen A. (1989). Sleep deprivation in the rat: IV. Paradoxical sleep deprivation. Sleep;12:22-30.

98. Locatelli V, Bresciani E, Tamiazzo L, Torsello A. (2010). Central nervous systemacting drugs influencing hypothalamic-pituitary-adrenal axis function. Endocr Dev; $17: 108-120$.

99. Lutter M, Sakata I, Osborne-Lawrence S, Rovinsky S, Anderson J. (2008). The orexigenic hormone ghrelin defends against depressive symptoms of chronic stress. Nat Neurosci; 11:752-753.

100. Machado R, Hipolide D, Benedito-Silva A, Tufik S. (2004). Sleep deprivation induced by the modified multiple platform technique: quantification of sleep loss and recovery. Brain Res; 1004: 45-51.

101. Majde J, Krueger J. (2005). Links between the innate immune system and sleep. J. Allergy Clin. Immunol; 116: 1188 - 1198.

102. Malik S, Kaplan J. (2005). Sleep deprivation. Prim. Care; 32:475:490.

103. Maniam J, Morris M. (2012). The link between stress and feeding behaviour. Neuropharmacol; 63(1): 97-110.

104. Martinez-Gonzalez D, Obermeyer W, Fahy J, Riboh M, Kalin N, Benca R. (2004). REM sleep deprivation induces changes in coping responses that are not reversed by amphetamine. Sleep; 27:609-17.

105. Martins P, Marques M, Tufik S, D'Almeida V. (2010). Orexin activation precedes increased NPY expression, hyperphagia, and metabolic changes in response to sleep deprivation. Am J Physiol Endocrinol Metab; 298(3):E726-34.

106. Marz W, Scharnagl H, Winkler K. (2004). Low-density lipoprotein triglycerides associated with low-grade systemic inflammation, adhesion molecules, and angiographic coronary artery disease: the Ludwigshafen Risk and Cardiovascular Health study. Circulation; 110:3068-3074.

107. Mastorakos G, Chrousos G, Weber J. (1993). Recombinant interleukin-6 activates the hypothalamic-pituitary-adrenal axis in humans. J Clin Endocrinol Metab; 77(6): 169094. 
108. Matsuzawa Y. (2006). Definition and history of metabolic syndrome. Nihon Rinsho; 28;64 Suppl 9:9-12.

109. McGinty D, Harper R. (1976). Dorsal raphe neurons: depression of firing during sleep in cats. Brain Res; 101: 569-575.

110. Meerlo P, Koehl M, Van der K, Turek F. (1974). Sleep restriction alters the hypothalamic-pituitary-adrenal response to stress. JNeuroendocrinol; 14 (5): 397-402.

111. Mendelson W, Guthrie R, Frederick G, Wyatt R. (1974). The flower pot technique of rapid eye movement (REM) sleep deprivation. Pharmacol Biochem Behav; 2:553-6.

112. Mitrakou A, Kelley D, Veneman T. (1990). Contribution of abnormal muscle and liver glucose metabolism to postprandial hyperglycemia in NIDDM. Diabetes; 39: 1381-90.

113. Mozid A, Tringali G, Forsling M, Hendricks M, Ajodha S. (2003). Ghrelin is released from rat hypothalamic explants and stimulates corticotrophin-releasing hormone and arginine-vasopressin. Horm Metab Res; 35:455-459.

114. Mullington J, Simpson N, Meier-Ewert H, Haack M. (2010). Sleep loss and inflammation. Best Pract Res Clin Endocrinol Metab; 24(5):775-84.

115. National Cholesterol Education Program. (2002). Third Report of the National Cholesterol Education Program (NCEP) Expert Panel of Detection, Evaluation of Treatment of High Blood Cholesterol in Adults (Adult Treatment Panel III) final report. Circulation; 106 (25): 3143-421.

116. National Center for Health Statistics. (2005). QuickStats: Percentage of adults who reported an average ofp6 $\mathrm{h}$ of sleep per24-hour period, by sex and age group-United States. Morb Mortal Wkly Rep.

117. Nauta W. (1964). Hypothalamic regulation of sleep in rats: an experimental study. $J$ Neurophysiol; 9: 285-316.

118. Nielsen T, Stenstrom P, Takeuchi T, Saucier S, Lara- Carrasco J, Solomonova E, Martel E. (2005). Partial REM-sleep deprivation increases the dream-like quality of mentation from REM sleep and sleep onset. Eep; 28(9):1083-9.

119. Nedeltcheva A, Kilkus J, Imperial J, Schoeller D, Penev P.(2010). Insufficient sleep undermines dietary efforts to reduce adiposity. Ann Intern Med; 153(7):435-441.

120. Nilsson P, Roost, Engstrom G, Hedblad B, Berglund G. (2004). Incidence of diabetes in middle-aged men is related to sleep disturbances. Diabetes Care; 27(10): 2464-2469.

121. Nobecourt E, Jacqueminet S, Hansel B, Chantepie S, Grimaldi A, Chapman MJ. (2005). Defective antioxidative activity of small denseHDL3 particles in type 2 diabetes: relationship to elevated oxidative stress and hyperglycaemia. Diabetologia; 48:529-38.

122. Nofzinger E, Buysse D, Miewald J. (2002). Human regional cerebral glucose metabolism during non-rapid eye movement sleep in relation to waking. Brain; 125:110515.

123. Oates M, Woodside B, Walker C. (2000). Chronic leptin administration in developing rats reduces stress responsiveness partly through changes in maternal behavior. Hormones and Behav; 37 366-376.

124. Ochi M, Tominaga K, Tanaka F, Tanigawa T, Shiba M. (2008). Effect of chronic stress on gastric emptying and plasma ghrelin levels in rats. Life Sci; 82:862-868.

125. Opp M. (2005). Cytokines and sleep. Sleep Med. Rev; 9:355 - 364.

126. Oral E, Simha V, Ruiz E. (2002). Leptin-replacement therapy for lipodystrophy. N Engl J Med; 346:570-8.

127. Papakonstantinou E, Ryan D, Harris R. (2003). Dietary fish oil does not protect rats exposed to restraint or sleep deprivation stress. Physiol Behav; 78: 759-765. 
128. Parish J, Adam T, Facchiano L. (2007). Relationship of metabolic syndrome and obstructive sleep apnea. J Clin Sleep Med; 3(5): 467-472.

129. Patchev V, Felszeghy K, Korányi L.(1991). Neuroendocrine and neurochemical consequences of long-term sleep deprivation in rats: similarities to some features of depression. Homeost Health Dis; 33(3):97-108.

130. Patel S, Zhu X, Storfer-Isser A, Mehra R, Jenny N, Tracy R, Redline S. (2009). Sleep duration and biomarkers of inflammation. Sleep; 32:200-4.

131. Patterson Z, Ducharme R, Anisman H, Abizaid A. (2010). Altered metabolic and neurochemical responses to chronic unpredictable stressors in ghrelin receptor-deficient mice. Eur J Neurosci; 32:632-639.

132. Peigneux P, Laureys S, Delbeuck X, Maquet P. (2001). Sleeping brain, learning brain. The role of sleep for memory systems. Neuroreport, 21;12(18):A111-24.

133. Perello M, Sakata I, Birnbaum S, Chuang J, Osborne-Lawrence S. (2010). Ghrelin increases the rewarding value of high-fat diet in an orexin-dependent manner. Biol Psychiatry; 67:880-886.

134. Perello M, Scott M, Sakata I, Lee C, Chuang J. (2011). Functional implications of limited leptin receptor and ghrelin receptor co-expression in the brain. J Comp Neurol; $1 ; 520(2): 281-94$.

135. Prinz P. (2004). Sleep, appetite, and obesity--what is the link? PLoS Med; 1: e61.

136. Próspero G, Drucker C. (1996). Control neural del ciclo vigilia-sueño: mecanismos neurofisiológicos y neuroquímicos. En: Ramos Platón MJ (Ed) Sueño y procesos cognitivos. Editorial Síntesis, Madrid; Pp 131-160.

137. Punjabi N, Shahar E, Redline S, Gottlieb D, Givelber R, Resnick H. (2004). Sleepdisordered breathing, glucose intolerance, and insulin resistance: the Sleep Heart Health Study. Am J Epidemiol ; 160:521-30.

138. Ratcliff R. (2009). Sleep deprivation affects multiple distinct cognitive processes Psychon Bull Rev August ; 16(4): 742-751.

139. Reaven G. (1988). Banting lecture 1988. Role of insulin resistance in human disease. Diabetes; 37:1595-607.

140. Reaven G. (2005). The insulin resistance syndrome: definition and dietary approaches to treatment. Annu Rev Nutr, 25:391-406.

141. Rechtschaffen A, Gilliland M, Bergmann B, Winter J. (1983). Physiological correlates of prolonged sleep deprivation in rats. Science; 221: 182-184.

142. Rechtschaffen A, Bergmann B. (1995). Sleep deprivation in the rat by the disk-overwater method. Behav Brain Res; 69:55-63.

143. Rechtschaffen A, Bergmann B. (2002). Sleep deprivation in the rat: an update of the paper. Sleep; 25:18-24.

144. Ranjabaran Z, Keefer L, Farhaid A, Stepanski E, Sedghi S, Keshavarzian A. (2009). Impact of sleep disturbances in inflammatory bowel disease. Sleep Med Rev 56(2): 36-44.

145. Rosa - Neto, Lira S, Venancio P, Cunha C, Oyam L, Pimentel D, Tufik S, Oller do Nascimento M, Santos V, T de Mello. (2010). Sleep deprivation affects inflammatory marker expression in adipose tissue. Lipids in Health and Disease; 9:125-131.

146. Rouach V, Bloch M, Rosenberg N, Gilad S, Limor R. (2007). The acute ghrelin response to a psychological stress challenge does not predict the post-stress urge to eat. Psychoneuroendocrinol; 32:693-702.

147. Savino F, Liguori SA, Fissore M, Oggero R, Silvestro L, Miniero R. (2005). Serum ghrelin concentration and weight gain in healthy term infants in the first year of life. $J$ Pediatr Gastroenterol Nutr, 41:653-9. 
148. Semba K, Fibinger H. (1992). Afferent connections of the laterodorsal and pedunculopontine tegmental nuclei in the rat: a retro- and antero-grade transport and inmunohistochemical study. J Comp Neurol; 323: 387-410.

149. Schmid S, Hallschmid M, Jauch-Chara K, Born J, Schultes B. (2008). A single night of sleep deprivation increases ghrelin levels and feelings of hunger in normal-weight healthy men. J Sleep Res; 17: 331-4.

150. Schultes B, Schmid S, Peters A, Born J, Fehm H. (2005). Sleep loss and development of diabetes: A review of current evidence. Exp Clin Endocrinol Diab; 113:15.

151. Schwartz M, Woods S, Porte D Jr, Seeley R, Baskin D. (2000). Central nervous system control of food intake. Nature; 404:661-71.

152. Sharma S, Kumpawat S, Goel A, Banga A, Ramakrishnan L, Chaturvedi P. (2007). Obesity, and not obstructive sleep apnea, is responsible for metabolic abnormalities in a cohort with sleep-disordered breathing. Sleep Med; 8:12-7.

153. Shearer W, Reuben J, Mullington J, Price N, Lee B, Smith E, Szuba M, Van Dongen H, Dinges D. (2001). Soluble TNF-alpha receptor 1 and IL-6 plasma levels in humans subjected to the sleep deprivation model of spaceflight. J Allergy Clin Immunol; 107:165-70.

154. Shiromani P, Kilduff T, Bloom F, McCarley R. (1992). Cholinergically induced REM sleep triggers Fos-like inmunoreactivity in dorsolateral pontine regions associated with REM sleep. Brain Res; 580: 351-357.

155. Smith S, Vale W. (2006). The role of the hypothalamic-pituitary-adrenal axis in neuroendocrine responses to stress. Dialogues Clin Neurosci; 8:383-395.

156. Siegel J.(2005). Clues to the functions of mammalian sleep. Nature; 437: 1264-1271.

157. Silber M, Ancoli-Israel S, Bonnet M, Chokroverty S, Grigg-Damberger M, Hirshkowitz M. (2007). The visual scoring of sleep in adults. J Clin Sleep Med; 3: 121.

158. Simon C, Gronfier C, Schlienger J, Brandenberger G. (1998).Circadian and ultradian variations of leptin in normal man under continuous enteral nutrition:

Relationship to sleep and body temperature. J Clin Endocrinol Metab; 83:1893-1899.

159. Skipski V. (1972). In Blood Lipids and Lipoproteins: Quantitation,C omposition and Metabolism, ed. G. J. Nelson; 471-583. NewY ork: Wiley-Interscience.

160. Slieker L, Sloop K, Surface P, Kriauciunas A, LaQuier F, Manetta J, BueValleskey J, Stephens T. (1996). Regulation of expression of ob mRNA and protein by glucocorticoids and cAMP. J Biol Chem; 271:5301-5304.

161. Spencer S, Xu L, Clarke M, Lemus M, Reichenbach A, Geenen B, Kozicz T, Andrews Z. (2012). Ghrelin regulates the hypothalamic-pituitary-adrenal axis and restricts anxiety after acute stress. Biol Psychiatry.

162. Spiegel K, Leproult R, Van Cauter E. (1999). Impact of sleep debt on metabolic and endocrine function. Lancet; 354: 1435-9.

163. Spiegel K, Tasali E, Penev P, Van Cauter E.(2004). Brief communication: sleep curtailment in healthy young men is associated with decreased leptin levels, elevated ghrelin levels, and increased hunger and appetite. Ann Intern Med; 141:846-50.

164. Spiegel K, Tasali E, Leproult R, Van Cauter E. (2009). Effects of poor and short sleep on glucose metabolism and obesity risk. Nat Rev Endocrinol; 5(5):253-261.

165. Stevanovic D, Milosevic V, Starcevic VP, Severs WB. (2007). The effect of centrally administered ghrelin on pituitary ACTH cells and circulating ACTH and corticosterone in rats. Life Sci; 80:867-872. 
166. Suchecki D, Antunes J, Tufik S. (2003). Palatable solutions during paradoxical sleep deprivation: reduction of hypothalamic-pituitary-adrenal axis activity and lack of effect on energy imbalance. J Neuroendocrinol; 15:815-21.

167. Suchecki D, Duarte Palma B, Tufik S. (2000). Sleep rebound in animals deprived of paradoxical sleep by the modified multiple platform method. Brain Res; 875(1-2):14-22.

168. Suchecki D, Tufik S.(2000). Social stability attenuates the stress in the modified multiple platform method for paradoxical sleep deprivation in the rat. Physiol Behav; 68(3):309-16.

169. Suchecki D, Tiba PA, Tufik S. (2002). Paradoxical sleep deprivation facilitates subsequent corticosterone response to a mild stressor in rats. Neurosci Lett; 320(1-2):458.

170. Taheri S, Lin L, Austin D, Young T, Mignot E. (2004). Short sleep duration is associated with reduced leptin, elevated ghrelin, and increased body mass index. PLoS Med; 1(3):e62.

171. Takaya K, Ariyasu H, Kanamoto N, Iwakura H, Yoshimoto A. (2000). Ghrelin strongly stimulates growth hormone release in humans. J Clin Endocrinol Metab; 85:4908-4911.

172. Trayhurn P, Wood IS. (2004). Adipokines: inflammation and the pleiotropic role of white adipose tissue. Br J Nutr; 92:347-355.

173. Trottier G, Koski KG, Brun T, Toufexis DJ, Richard D \& Walker CD. (1998). Increased fat intake during lactation modifies hypothalamic-pituitary-adrenal responsiveness in developing rat pups: a possible role for leptin. Endocrinol; 139 37043711.

174. Tschop M, Wawarta R, Riepl R, Friedrich S, Bidlingmaier M. (2001). Post-prandial decrease of circulating human ghrelin levels. J Endocrinol Invest; 24:RC19-21.

175. Tuomilehto H, Peltonen M, Patinen M, Seppa J, Saaristo T, Korpi-Hyovalti E, Oksa H, Puolijoki H, Saltevo J, Vanhala M, Tuomilehto J. (2007). Sleep duration is associated with an increased risk of type 2 diabetes in middle-aged women-The FIN-D2D survey. Sleep Med; 17:S13899457.

176. Uthgenannt D, Schoolmann D, Pietrowsky R, Fehm H, Born J. (1995). Effects of sleep on the production of cytokines in humans. Psychosom Med; 57(2):97-104.

177. Van Cauter E, Blackman J, Roland D, Spire J, Refetoff S, Polonsky K.(1991). Modulation of glucose regulation and insulin secretion by circadian rhythmicity and sleep. J Clin Invest; 88:934-942.

178. Van Cauter E, Polonsky K, Scheen AJ. (1997). Roles of circadian rhythmicity and sleep in human glucose regulation. Endocr Rev; 18(5):716-738.

179. Van Cauter E, Spiegel K. (1999). Regulation of sleep and circadian rhythms. In: Turek FW, Zee P, eds. Circadian and sleep control of hormonal secretion. New York: Basel; 397-425.

180. Van Helder, Radomski. (2003). World Health Organization.

181. Van der Lely A, Tschop M, Heiman M, Ghigo E. (2004). Biological, physiological, pathophysiological, and pharmacological aspects of ghrelin. Endocr Rev; 25:426457.

182. Vázquez P, Velazquez M. (2000). Effect of electric foot shocks, immobilization, and corticosterone administration on the sleep-wake pattern in the rat. Physiol Behav; $15 ; 71(1-2): 23-8$

183. Vázquez P, Retana M, Bonilla J, Velázquez M. (2001). Further definition of the effect of corticosterone on the sleep-wake pattern in the male rat. Pharmacol Biochem Behav; 70(2-3):305-10. 
184. Velásquez M, Rosas P, Laraesqueda A, Pastelín H. (2002). Hipertensión Arterial en México: Resultados de la Encuesta Nacional de Salud (ENSA) 2000. Arch Cardiol Mex; 72: 71-84.

185. Vgontzas A, Papanicolaou D, Bixler E, Lotsikas A, Zachman K, Kales A, Prolo P, Wong M, Licinio J, Gold P, Hermida R, Mastorakos G, Chrousos G. (1999). Circadian interleukin- 6 secretion and quality and depth of sleep. J Clin Endocrinol Metab; 84(8):2603-7.

186. Vgontzas A, Zoumakis E, Bixler E. (2004). Adverse effects of modest sleep restriction on sleepiness, performance, and inflammatory cytokines. Journal of Clinical Endocrinology \& Metabolism; 89:2119-26.

187. Vgontzas A, Bixler E, Lin H, Prolo P, Trakada G, Chrousos G. (2005). IL-6 and its circadian secretion in humans. Neuroimmunomodulat; 12, $131-140$.

188. Vgontzas A, Pejovic S, Zoumakis E, Lin H, Bixler E, Basta M, Fang J, Sarrigiannidis A, Chrousos G. (2007a). Daytimenapping after a night of sleep loss decreases sleepiness, improves performance, and causes beneficial changes in cortisol and interleukin-6 secretion. Am J Physiol Endocrinol Metab; 292(1):E253-61.

189. Wajchenberg B. (2000). Subcutaneous and visceral adipose tissue: their relation to the metabolic syndrome. Endocr Rev; 21:697-738.

190. Walker J, Berger R. (1980). Sleep as an adaptation for energy conservation functionally related to hibernation and shallow torpor. Prog Brain Res; 53:255-278.

191. Weikel J, Wichniak A, Isling M, Brunner H, Freiss E, Held K, Mathias S, Schmid S, Uhr M, Steiger A. (2003). Ghrelin promotes slow wave sleep in humans. Am. J. Endocrinol. Metab; 284, E407-E415.

192. Williams C, Hu F, Patel S, Mantzoros C. (2007). Sleep duration and snoring in relation to biomarkers of cardiovascular disease risk among women with type 2 diabetes. Diabetes Care; 30:1233-40.

193. Willie J, Chemelli R, Sinton C, Yanagisawa M. (2001). To eat or to sleep? Orexin in the regulation of feeding and wakefulness. Annu Rev Neurosci; 24: 429-58.

194. Wilson M, Fisher J, Brown J. (2005). Chronic subcutaneous leptin infusion diminishes the responsiveness of the hypothalamic-pituitary-adrenal (HPA) axis in female rhesus monkeys. Physiol and Behav; 84 449-458.

195. Wren A, Small C, Fribbens C, Neary N, Ward H. (2002). The hypothalamic mechanisms of the hypophysiotropic action of ghrelin. Neuroendocrinol; 76:316-324.

196. Yaggi H, Araujo A, McKinlay J. (2006). Sleep duration as a risk factor for the development of type 2 diabetes. Diabetes Care; 29:657-61.

197. Yehuda S, Sredni B, Carrasco RL, Kenigsbuch-Sredni D. (2009) REM sleep deprivation in rats results in inflamation and interleukin-17 elevation. J Interferon Cytokine Res; 29:393-8.

198. Young T. (1993). Analytic epidemiology studies of sleep disordered breathing - what explains the gender difference in sleep disordered breathing?. Sleep; 16(8 Suppl) S1-2.

199. Youngblood BD, Smagin GN, Elkins PD, Ryan DH, Harris RB. (1999). The effects of paradoxical sleep deprivation and valine on spatial learning and brain 5-HT metabolism. Physiol Behav; 67(5):643-9.

200. Zaninovich A. (2005). Rol de las proteínas desacoplantes UCP1, UCP2 y UCP3 en el gasto energético, diabetes tipo 2 y obesidad: sinergismo con la tiroides. MEDICINA (Buenos Aires); 65: 163-169.

201. Zhao T, Liang G, Li R, Xie X, Sleeman M, Murphy A, Valenzuela D, Yancopoulos G, Goldstein J, Brown M. (2010). Ghrelin O-acyltransferase (GOAT) is essential for 
growth hormone-mediated survival of calorie-restricted mice. Proc Natl Acad Sci U S A; 107(16):7467-72.

202. Zhang F, Chen Y, Heiman M, Dimarchi R. (2005) Leptin: structure, function and biology Vitam. Horm; 71,345-372. 
EFECTO DE LA PRIVACION DE SUEÑO MOR SOBRE MARCADORES METABOLICOS E INFLAMATORIOS EN RATAS

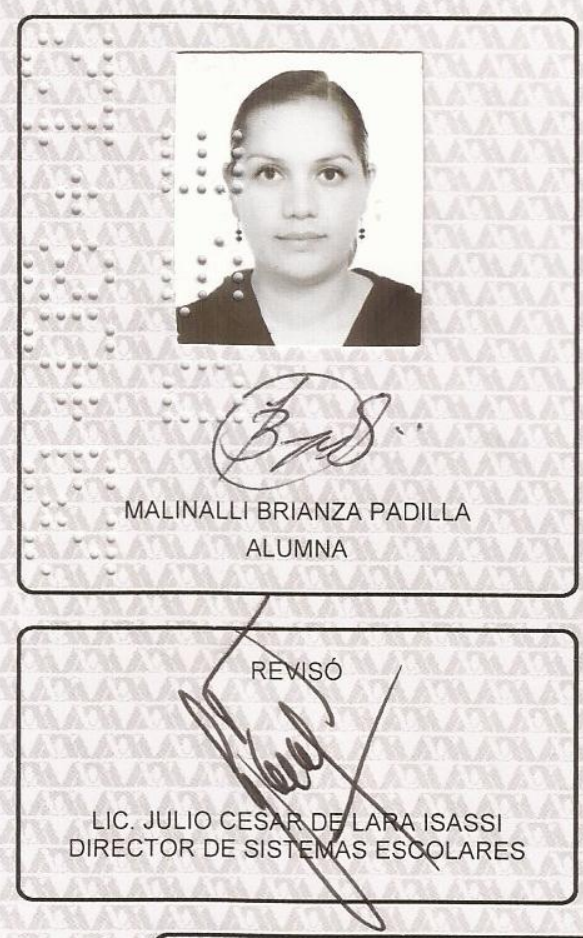

Bajo la Presidencia del primero y con carácter de Secretario el último, se reunieron para proceder al Examen de Grado cuya denominación aparece al margen, para la obtención del grado de:

MAESTRA EN BIOLOGIA EXPERIMENTAL

DE: MALINALLI BRIANZA PADILLA

y de acuerdo con el artículo 78 fracción III del Reglamento de Estudios Superiores de la Universidad Autónoma Metropolitana, los miembros del jurado resolvieron:

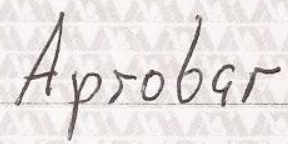

Acto continuo, el presidente del jurado comunicó a la interesada el resultado de la evaluación y, en caso aprobatorio, le fue tomada la protesta.
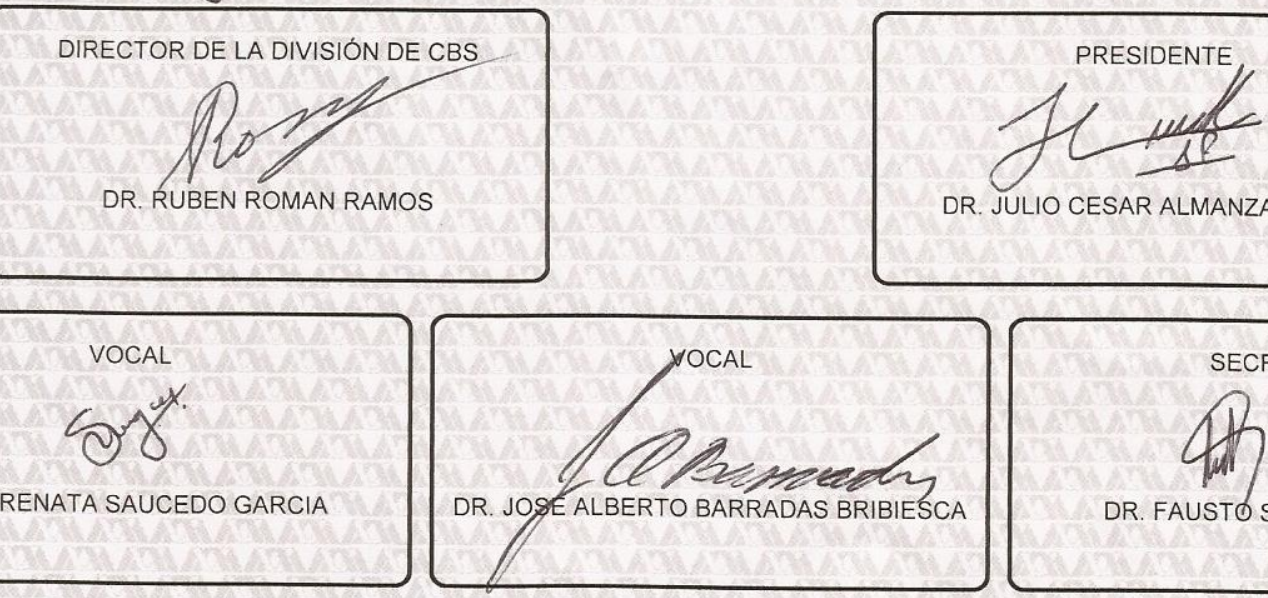

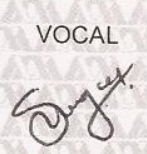

DRA. RENATA SAUCEDO GARCIA

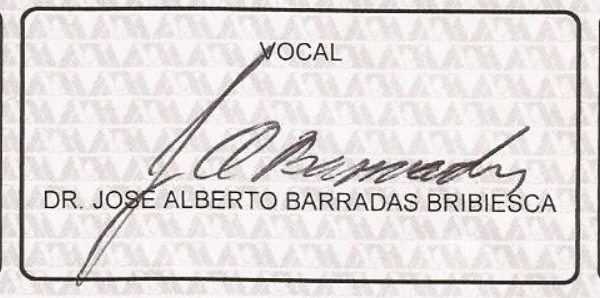

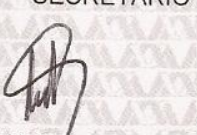

DR. FAUSTO SANCHEZ MUNOZ 